\title{
Dentognathic remains of Australopithecus afarensis from Nefuraytu (Woranso-Mille, Ethiopia): Comparative description, geology, and paleoecological context
}

Yohannes Haile-Selassie ${ }^{1,2,{ }^{*},}$ Stephanie M. Melillo ${ }^{3}$, Timothy M. Ryan ${ }^{4}$, Naomi E. Levin ${ }^{5}$, Beverly Z. Saylor ${ }^{6}$, Alan Deino ${ }^{7}$, Ronald Mundil ${ }^{7}$, Gary Scott ${ }^{7}$, Mulugeta Alene ${ }^{8}$, Luis Gibert ${ }^{9}$

${ }^{1}$ Department of Physical Anthropology, Cleveland Museum of Natural History, 1 Wade Oval Drive, Cleveland, OH 44106, USA

${ }^{2}$ Departments of Anthropology, Anatomy, and Cognitive Sciences, Case Western Reserve University, 10900 Euclid Avenue, Cleveland, OH 44106, USA

${ }^{3}$ Max Plank Institute for Evolutionary Anthropology, Department of Human Evolution, Deutscher Platz 6, D-04103 Leipzig, Germany

${ }^{4}$ Pennsylvania State University, University Park, PA 16802, USA

${ }^{5}$ Department of Earth and Environmental Sciences, University of Michigan, Ann Arbor, MI 48109, USA

${ }^{6}$ Department of Earth, Environmental, and Planetary Sciences, Case Western Reserve University, 10900 Euclid Avenue, Cleveland, OH 44106, USA

${ }^{7}$ Berkeley Geochronology Center, 2455 Ridge Road, Berkeley, CA 94709, USA

${ }^{8}$ School of Earth Sciences, Addis Ababa University, PO Box 1176, Addis Ababa, Ethiopia

${ }^{9}$ University of Barcelona, Martí Franquès s/n, 08028 Barcelona, Spain

*Corresponding Author

email: yhaileselassie@cmnh.org 


\begin{abstract}
Australopithecus afarensis is the best-known and most dimorphic species in the early hominin fossil record. Here, we present a comparative description of new fossil specimens of $A u$. afarensis from Nefuraytu, a 3.330-3.207 million-years-old fossil collection area in the WoransoMille study area, central Afar, Ethiopia. These specimens include NFR-VP-1/29, one of the most complete mandibles assigned to the species thus far and among the largest mandibles attributed to $A u$. afarensis, likely representing a male individual. NFR-VP-1/29 retains almost all of the distinctive archaic features documented for Au. afarensis. These features include a posteriorly sloping symphysis, a low and rounded basally set inferior transverse torus, anterosuperiorly opening mental foramen, a lateral corpus hollow bound anteriorly by the $\mathrm{C} / \mathrm{P}_{3}$ jugae and posteriorly by the lateral prominence, and the ascending ramus arising high on the corpus. Dental morphology and metrics of the Nefuraytu specimens also falls within the range of Au. afarensis. The presence of this species at Woranso-Mille between 3.330-3.207 million years ago confirms the existence of this species in the area in close spatial and temporal proximity to other middle Pliocene hominin taxa such as the one represented by the Burtele foot (BRT-VP-2/73) and the recently named species $A u$. deyiremeda. This has important implications for our understanding of middle Pliocene hominin diversity.
\end{abstract}

Keywords: Australopithecus afarensis, hominin diversity, Nefuraytu, Woranso-Mille, Ethiopia 


\section{Introduction}

Australopithecus afarensis is one of the best known hominin species in the Pliocene fossil record and hypothesized as the direct descendant of the 4.2-3.9 Ma Australopithecus anamensis (Leakey et al., 1995, 1998; Ward et al., 2001; White et al., 2006). Its remains have been recovered from sites in Ethiopia, Kenya, and Tanzania from deposits ranging in age from 3.7-2.9 million years ago (Ma) (Johanson and Taieb, 1976; Taieb et al., 1976; Johanson et al., 1978a,b, 1982a-c; Kimbel and White, 1988; Kimbel et al., 1985, 1994, 2004; White et al., 1993, 2000; Brown et al., 2001; Kimbel and Delezene, 2009; Harrison, 2011; Mbua et al., 2016). The best sample of the species comes from Hadar, in the Afar region of Ethiopia, where hundreds of specimens representing males and females of juvenile and adult individuals have been recovered since the early 1970s (Johanson and Taieb, 1976; Johanson et al., 1978a,b, 1982a-c; Kimbel et al., 1994, 2004). The large sample size and presence of Au. afarensis in a continuous stratigraphic succession at Hadar has been instrumental in addressing questions related to sexual dimorphism (Kimbel and White, 1988; Kimbel et al., 1994; Lockwood, et al. 1996) and temporal trends in morphological variation in the species (Lockwood et al., 2000).

Multidisciplinary investigations at the Woranso-Mille paleontological study area (Fig. 1), located north of Hadar (Taieb et al., 1976) and Ledi-Geraru (Dupont-Nivet et al., 2008), were initiated in 2004 (Haile-Selassie et al., 2007). Some of the areas within the Woranso-Mille study area were visited in the 1970s by members of the Rift Valley Research Mission in Ethiopia (RVRME), who collected fossil remains (mostly suids and cercopithecids) from various localities (Kalb, 2001). Since 2004, the Woranso-Mille project has thus far collected more than 9,000 vertebrate fossil specimens from more than 85 identified localities ranging in age from > 5.4 Ma to ca. 3 Ma. More than 65 mammalian taxa, including a number of species that are new 
to science, have been identified as of the end of the 2015 field season. Of the total number of fossil specimens collected thus far, ca. 145 specimens belong to multiple early hominin taxa, most of which are dated to between 3.8 and 3.2 Ma (Deino et al., 2010; Haile-Selassie, 2010; Haile-Selassie et al., 2010a,b, 2012, 2015; Levin et al., 2015; Saylor et al., 2016a,b). These include cf. Au. anamensis, Au. afarensis and Au. deyiremeda (Haile-Selassie, 2010; HaileSelassie et al., 2010a,b, 2015). In addition, the Burtele partial foot (BRT-VP-2/73), currently not assigned to a taxon (Haile-Selassie et al., 2012), may represent an already known early hominin from the Afar region other than Au. afarensis (i.e. Ardipithecus ramidus, Au. anamensis or $A u$. deyiremeda) or a species currently unknown from dentognathic remains (Haile-Selassie et al., 2015).

The 2005 discovery at Korsi Dora (Woranso-Mille) of the ca. 3.6 Ma partial skeleton assigned to $A u$. afarensis (KSD-VP-1/1; "Kadanuumuu"), a species well-represented at Hadar, extended the species' geographic distribution by ca. 45 kilometers $(\mathrm{km})$ north of Hadar. In addition to being the geochronologically oldest partial skeleton of an adult $A u$. afarensis and one of the largest individuals of the species, KSD-VP-1/1 also preserves the most complete adult scapula of the species. Together with the 3.3 Ma juvenile scapulae of DIK-1-1 (Alemseged et al., 2006; Green and Alemseged, 2012), the KSD-VP-1/1 scapula has helped us to further understand the shoulder girdle anatomy of the species (Melillo, 2011, 2016).

The new Au. afarensis dentognathic remains described here come from Nefuraytu (NFRVP-1), a vertebrate locality in the north-central Woranso-Mille study area (Fig. 1). Nefuraytu was first surveyed in 2007, and 342 mammalian fossil remains, including six hominin specimens, have been cataloged to date. The hominin fossils described here (Fig. 2) derive from three fossiliferous horizons within a $>40 \mathrm{~m}$ stratigraphic section. Magnetostratigraphic and radiometric 
dating $\left({ }^{40} \mathrm{Ar} /{ }^{39} \mathrm{Ar}\right.$ on feldspar and $\mathrm{U} / \mathrm{Pb}$ on zircon $)$ indicate that the deposition of the NFR-VP-1 fossils occurred during the Mammoth paleomagnetic subchron (C2An.2r, with an astronomically calibrated age of 3.330-3.207 Ma; Lourens, et al. 2004; see discussions below).

\section{Geological context and age}

\section{Lithology}

A $44 \mathrm{~m}$ thick composite section was measured at Nefuraytu (Fig. 3). Three fossiliferous horizons at 18, 25 and $32 \mathrm{~m}$ above the base are associated with sandstones. The lithology of these sections consists of siltstone and claystone (including pedogenic carbonate) interstratified with fine-grained sandstones. Between 13-19 m a coarse detrital unit consists of coarse sandstone and gravel. The gravel, located $3 \mathrm{~m}$ below the lower fossiliferous bed, contains cobbles up to 15 $\mathrm{cm}$ in diameter.

\section{Chronostratigraphy}

The Nefuraytu sequence is isolated stratigraphically in that no direct connection to underlying or overlying strata can be observed. However, projection of the $\sim 1^{\circ} \mathrm{E}$ dipping Nefuraytu strata, $\sim 3 \mathrm{~km}$ westward towards Burtele (Haile-Selassie et al., 2015) indicates that the Nefuraytu strata are younger than the sequence at Burtele, in the absence of structural folds or flexures. Geochronological measurements and paleomagnetic stratigraphy (see below) support this inference and suggest that little if any strata are missing in the Burtele through Nefuraytu sequence.

\section{Geochronology}

Two thin $(0-4 \mathrm{~cm})$ reworked pumice tuff horizons are exposed in the lower third of the Nefuraytu section within a narrow $(\sim 20-30 \mathrm{~cm})$ stratigraphic interval. Typically the pumice 
clasts are $<1 \mathrm{~cm}$, well-rounded, have a stretched bubble-wall texture, and are nearly aphyric but contain rare feldspar, zircon, biotite and apatite. An unusual feature of these tuffs is that the original volcanic glass is completely altered diagenetically to a white waxy clay or zeolite that dissolves immediately upon exposure to water. Shard pseudomorph textures are preserved, as observed microscopically. Attempts to extract enough feldspar of sufficient size for ${ }^{40} \mathrm{Ar} /{ }^{39} \mathrm{Ar}$ dating from the fine pumice were unsuccessful, so bulk-tuff extractions were processed and analyzed. A total of 151 single-crystal total-fusion ${ }^{40} \mathrm{Ar} /{ }^{39} \mathrm{Ar}$ analyses were acquired from two samples (WM07/N-1 from the lower tuff and WM07/N-2 from the upper). Procedures and methods are similar to those detailed in Deino et al. (2010). Sanidine from the Fish Canyon Tuff with a reference age of $28.198 \pm 0.044 \mathrm{Ma}$ was used (Kuiper et al., 2008), decay constants were those of Steiger and Jäger (1977), and atmospheric argon compositions were according to Lee et al. (2006).

The ${ }^{40} \mathrm{Ar}{ }^{39} \mathrm{Ar}$ results are presented as age probability-density spectra in Fig. 4 (see SOM A for complete data). Based on the inferred stratigraphic position of the Nefuraytu section from its proximity to the dated Burtele section as discussed above, and newly acquired magnetostratigraphy, we infer that the Nefuraytu section occupies the Mammoth reversed intervals in the Gauss chron, between 3.330-3.207 Ma (Lourens et al., 2004). However, virtually all of the ${ }^{40} \mathrm{Ar} /{ }^{39} \mathrm{Ar}$ results are older, and, given the reworked nature of the tuffs, likely reflect detrital contaminants. These xenocrystic components yield ages typical for the Woranso-Mille area, in particular reflecting early rift volcanism in the late Oligocene, and what are likely major proximal volcanic events at $\sim 4.8$ and $\sim 7 \mathrm{Ma}$ (Deino et al., 2010; Saylor et al., 2016b). Younger ages are present, but uncertainties in many cases are largely due to low $\mathrm{K}$ content and small grain size. Extracting just the analyses with an uncertainty of $<1.5 \mathrm{Ma}$, and excluding likely detrital 
material with an age of $>4.5 \mathrm{Ma}$, yields the probability-density curves shown in the inset in Fig. 4. The youngest population from WM07/N-1 gives a weighted-mean age of $3.73 \pm 0.05 \mathrm{Ma}(n=$ 7), which is too old in reference to the known chronostratigraphy, but provides a maximum age. Sample WM07/N-1 gives a weighted-mean age of $3.41 \pm 0.21 \mathrm{Ma}(n=3)$. While this result is probably nearly correct in magnitude, the uncertainty is large, as it is derived from just a few small plagioclase crystals $(\mathrm{Ca} / \mathrm{K}=3.2-9.5$; lab numbers $25040-09,-13$, and 25029-64, SOM A). However, $\mathrm{U} / \mathrm{Pb}$ dating of the tuff yields a similar age (see below).

\section{U-Pb dating}

Sample WM12/N-1 (=WM07/N-1) is a tuff from the base of the Nefuraytu section. Magnetostratigraphic analyses suggest that it was deposited within a reversed interval (see section on Magnetostratigraphy). Small zircon crystals were separated from the tuff and subjected to single crystal ID-TIMS (isotope dilution-thermal ionization mass spectrometry) and a 3 dimensional total $\mathrm{Pb} / \mathrm{U}$ isochron, constrained by 6 analyses, yields an age of $3.373 \pm 0.047$ Ma (here we report a 2 sigma uncertainty for consistency throughout the study), within uncertainty of an age of 3.330 Ma for the age of the base of subchron 2An.2r (=Mammoth) (Lourens et al., 2004) (Fig. 5; SOM B). Excess scatter in the zircon ages most likely results from protracted zircon crystallization at 10-20 ka level prior to eruption and deposition of the tuff, which is consistent with the finding that the isochron age of 3.369 Ma predates the age for the base of subchron 2An.2r, but eruption and deposition of the tuff occurred within and near the base of the latter (see SOM C for further details).

\section{Magnetostratigraphy}

Eight stratigraphic layers were sampled for polarity zonation at the Nefuraytu section (Fig. 3). The top sample (at $41 \mathrm{~m}$ ) yielded normal polarity while the remainder of the section is 
reversed. Five additional samples were collected at a shorter $(25 \mathrm{~m})$, overlapping section located $2 \mathrm{~km}$ east, where all samples yielded reverse polarity. The nearby Burtele sequence is paleomagnetically normal, and is anchored in the next earlier chron by the precisely dated Burtele tuff at $3.469 \pm 0.008 \mathrm{Ma}$ (Haile-Selassie et al., 2012, 2015). These relationships suggest that the long $(>35 \mathrm{~m})$ reverse polarity zone recorded by all but the uppermost strata at Nefuraytu belong within a younger reversal, most likely the Mammoth subchron (C2An.2r, 3.330-3.207 Ma; Lourens, et al. 2004). This chronological interpretation of the polarity sequence is based on: a) the apparent stratigraphic continuity to other sections; b) a general age limit of $\sim<3.7 \mathrm{Ma}$ [from ${ }^{40} \mathrm{Ar} /{ }^{39} \mathrm{Ar}$ ]; and c) an maximum age of $3.37 \mathrm{Ma}$ [from U-Pb on zircons].

\section{Associated fauna and paleoenvironment}

Preservation of the fossils and taxonomic abundance in all three fossiliferous horizons at NFR are very similar. Partial skeletons of large mammals such as elephants, hippopotamuses, and rhinoceroses and complete crania of bovids are present, showing no sign of substantial carnivore ravaging or long distance transportation. All three horizons are associated with significant numbers of aquatic fauna such as fish and crocodiles. This indicates not only the presence of abundant water at all levels, but also homogeneity in depositional environments across all three horizons. Pending detailed taphonomic analyses, the high number of partial skeletons and lack of carnivore ravaging suggest that the animals were likely quickly buried after death in a low energy environment.

The faunal assemblage from NFR-VP-1 includes $>30$ mammalian taxa and at least two aquatic avian species (Table 1). Terrestrial and aquatic reptiles are also common in addition to fish, gastropods, and bivalves. Papionines (particularly Theropithecus oswaldi) are the most abundant among the cercopithecids (14\% of the total fauna and $90.1 \%$ of the cercopithecids), 
while colobines are rare (1.5\% of the total fauna and $9.9 \%$ of the cercopithecids). Among the specimens identified to a subfamily level, tragelaphins and aepycerotins ( $35.6 \%$ of the bovid assemblage) are abundant, each represented by at least two species. Only a single specimen of an alcelaphin has been recovered from the lower fossiliferous horizon and antilopins, neotragins, and reduncins are rare across all horizons $(7.8 \%$ of the bovid assemblage identified to a subfamily level). The suid species Notochoerus euilus and Kolpochoerus afarensis are relatively abundant ( $24 \%$ of the total NFR faunal assemblage). Carnivores constitute $7 \%$ of the total NFR faunal assemblage. Among the carnivores, a large mustelid (Enhydriodon sp.) is present and the felids and hyaenids are represented by cf. Dinofelis sp. and cf. Crocuta sp., respectively. An unreferred canid is also known from two specimens.

Comparison of the NFR mammalian faunal assemblage with the fauna from the underlying sequence at Burtele, ca. $3 \mathrm{~km}$ to the west, shows significant taxonomic similarity, although the high relative abundance of alcelaphins and the presence of the suid Nyanzachoerus kanamensis at the Burtele localities (BRT-VP-1 and BRT-VP-2; see Haile-Selassie et al., 2012 for details) are noticeable differences. Some of the hominin specimens at BRT also represent a species distinct from Au. afarensis. Further comparisons with contemporaneous strata at Hadar (SH-4 and DD-1), ca. $45 \mathrm{~km}$ to the south, show that there are more mammalian taxa at NFR than at the contemporaneous Hadar SH-4 and DD-1 levels, although there are overlaps in some taxa (Table 1). Most of the tragelaphin, aepycerotin, and suid species present at NFR are also present at Hadar (Reed, 2008; Reed and Bibi, 2011). However, some bovid taxa that are present at Hadar are absent at NFR (e.g., Ugandax, Parmularius, Damalops). Generally, the bovid community at NFR appears to be slightly different from both the underlying BRT and contemporaneous levels 
at Hadar. Understanding the causes for these apparent differences requires detailed analyses of these faunal assemblages in a paleoecological context.

Based on lithology and stratigraphy, we interpret the depositional environment at NFR as a distal fluvial plain, where episodic flooding deposited fine-grained overbank sediments that were exposed long enough for soil development to occur. The coarse sediments represent fluvial channel deposits. The presence of pedogenic carbonate in many of the soils that developed on these fluvial plains indicates seasonally dry environments at NFR.

Stable carbon isotope data from fossil teeth (Table 2) and pedogenic carbonates (Table 3) from NFR provide additional perspective on the environments in which the hominins and other mammals at NFR were deposited and lived. These data were initially reported in Levin et al. (2015) as part of a broader study on hominin and cercopithecid dietary change at Woranso-Mille but here we highlight the results from samples collected at NFR. All carbon isotope data are reported in $\delta$-notation where $\delta^{13} \mathrm{C}=\left(\mathrm{R}_{\text {sample }} / \mathrm{R}_{\mathrm{VPDB}}-1\right) \times 1000$ and per mil $(\%)$ units, where $\mathrm{R}_{\text {sample }}$ and $\mathrm{R}_{\mathrm{VPDB}}$ represent the ratio of ${ }^{13} \mathrm{C}$ and ${ }^{12} \mathrm{C}$ in the sample and standard Vienna Pee Dee Belemnite, respectively. The methods used for the stable isotope analysis of the pedogenic carbonates and fossil teeth from NFR are reported in Levin et al. (2015), where guidelines for interpreting the data are also provided. Pedogenic carbonates were sampled from four soil horizons at NFR (Fig. 3). However not all of the sampled horizons match intervals of pedogenic development on the composite section due to lateral variability in the lithology at NFR, typical of fluvial systems. The $\delta^{13} \mathrm{C}$ values of pedogenic carbonates from NFR decrease upward from $-2.5 \%$ at the base of the section to $-11.5 \%$ at the top (Fig. 3), indicating a landscape dominated by $\mathrm{C}_{4}$ vegetation prior to deposition of the lower fossil horizon and mixed $\mathrm{C}_{3}-\mathrm{C}_{4}$ to $\mathrm{C}_{3}$-dominated landscapes in the middle and upper portions of the section. 
Carbon isotope data from the teeth of hominins $(n=1)$, bovids $(n=4)$, giraffids $(n=3)$ and the suid Not. euilus $(n=11)$ from NFR indicate that grazers (Not. euilus), browsers (giraffids, unidentified bovid) and mixed feeders (tragelaphins) are represented in this sample. We do not have enough data to identify differences in the carbon isotope data from teeth sampled from the three fossiliferous horizons at NFR. The single hominin sampled from the lower fossiliferous horizon (NFR-VP-1/213; see Table 2) yields a $\delta^{13} \mathrm{C}$ value of $-9.1 \%$, which indicates a diet dominated by $\mathrm{C}_{3}$ foods. This may reflect a preference for $\mathrm{C}_{3}$ resources by the hominins at NFR despite the availability of $\mathrm{C}_{4}$ vegetation, which is indicated by both the carbon isotope data from other mammals and pedogenic carbonates. For comparison, the $\delta^{13} \mathrm{C}$ value of the NFR hominin is within the range of the other mid-Pliocene hominins at Woranso-Mille which have a median value $-7.5 \%$ (mean $-7.9 \pm 2.5 \%$, range -11.8 to $-3.8 \%, n=16$ ) and may represent multiple species (Levin et al., 2015). Overall, the $\delta^{13} \mathrm{C}$ values from the Woranso-Mille hominins are significantly higher than those of $A u$. anamensis but they are indistinct from those from $A u$. afarensis and younger hominins (see Levin et al., 2015 and Cerling et al., 2013, for further details).

\section{The Nefuraytu (NFR-VP-1) fossil hominins}

Six hominin specimens were recovered from NFR-VP-1 between 2007 and 2011 (Fig. 2). Among these specimens is an almost complete mandible with most of the dentition (NFR-VP1/29; Figs. 2A-D). The isolated teeth include two complete lower molar crowns (NFR-VP-1/2 and NFR-VP-1/58), an upper third molar (NFR-VP-1/213) (Figures 2E-G), and a lower canine fragment (NFR-VP-1/96). A small piece of the cranial vault (NFR-VP-1/214) has also been recovered. NFR-VP-1/96 and NFR-VP-1/214 are too fragmentary for detailed comparative analysis. These specimens, together with the two isolated teeth, cannot be assigned to any 
specific species with confidence, largely due to the presence of more than one hominin species at Woranso-Mille at 3.5-3.3 Ma. Therefore, they are provisionally referred here to Australopithecus sp. Anatomical terminology used in the description of the NFR specimens follows Johanson et al. (1982) and abbreviations are provided in Table 4.

\section{Comparative morphological description}

NFR-VP-1/29: Mandible (left $\mathrm{I}_{2}, \mathrm{P}_{4}-\mathrm{M}_{3} ;$ right $\mathrm{P}_{4}-\mathrm{M}_{3}$ ) (Figs. 2A-D)

Discovery and preservation The right half of the mandible was found on the surface. The lingual half of the $M_{1}$ and the complete $M_{2}$ were still attached to the mandible. The left half of the mandible was found after 12 days of surface scraping and sieving. None of the teeth was present on the corpus. All of the left mandibular teeth $\left(\mathrm{I}_{2}, \mathrm{P}_{4}-\mathrm{M}_{3}\right)$ and the right $\mathrm{P}_{4}$ and $\mathrm{M}_{3}$ were found by sieving. Anteriorly, the mandible was broken at the right $\mathrm{I}_{2} / \mathrm{c}$ level. The roots of the right $\mathrm{I}_{2}-\mathrm{P}_{4}$ and $M_{3}$ are visible on the mandible. The ascending ramus is broken immediately behind the $\mathrm{M}_{3}$. The root of the ascending ramus is flaked along its anterior edge. The canine socket lacks small bony surface around the alveolus. A thin crack runs from the alveolar region between the $\mathrm{P}_{4}$ and $\mathrm{M}_{1}$ infero-posteriorly toward the base of the lateral corpus. However, this crack has not altered the morphology of the lateral corpus. Anteriorly, a bony surface is missing around the right $\mathrm{I}_{2}$ and the canine area obscuring the alveolar margin. The ascending ramus is also missing on this side. It is broken immediately behind the $\mathrm{M}_{3}$ and the distal root of the $\mathrm{M}_{3}$ and the root of the ascending ramus are also missing. All of the recovered postcanine crowns (except the right $\mathrm{M}_{1}$ which is missing its buccal half) are preserved intact.

Occlusal aspect The dental arcade shape of Au. afarensis mandibles is highly variable (see Kimbel and Delezene, 2009 for details). NFR-VP-1/29 falls within the range of variation of $A u$. afarensis in this regard. It is slightly more open posteriorly than in A.L. 400-1a, MAK-VP-1/12, 
and L.H.-4 but not as 'v-shaped' as in A.L. 288-1 (see Fig. 6). NFR-VP-1/29 has dimensions of ca. $18.5 \mathrm{~mm}$ between the canine alveoli and $42.3 \mathrm{~mm}$ at the $\mathrm{M}_{3} \mathrm{~s}$ most lingual points, compared to $21.2 \mathrm{~mm}$ and $34.8 \mathrm{~mm}$ in A.L. $400-1$ a, ca. $20.2 \mathrm{~mm}$ and ca. $38.0 \mathrm{~mm}$ in MAK-VP-1/12, and $22.3 \mathrm{~mm}$ and $39.0 \mathrm{~mm}$ in L.H.-4, respectively. In superior view, the incisor alveoli appear to be lined up in almost a straight line and do not form a well-defined arc as in most $A u$. afarensis mandibles. The postcanine tooth row is straight and the occlusal wear plane is heliocoidal as in most $A u$. afarensis mandibles even though the lingual tilt of the $\mathrm{M}_{3} \mathrm{~s}$ is particularly pronounced in the NFR mandible. Based on preserved roots, the incisors and canines appear to have been implanted vertically. The anterior symphysis to lateral corpus transition occurs at the canine level with a sharp bend and the $\mathrm{P}_{3}$ root does not have a noticeable contribution in the transition. This is a condition also seen in L.H.-4, but is unlike most Au. afarensis mandibles where the transition is accomplished across an even curve in which both the canine and $\mathrm{P}_{3}$ roots contribute (White et al., 2000). The superior and inferior transverse tori are well-developed particularly at the $\mathrm{P}_{3}$ and $\mathrm{P}_{4}$ levels. This discrete trait is also seen in some Au. afarensis mandibles (Kimbel et al., 2004), although most are nearly vertical in this region. When viewed occlusally, the $\mathrm{P}_{4} \mathrm{~S}$ of NFR-VP$1 / 29$ are set distal to the postero-inferior edge of the symphysis as in A.L. 438-1g, A.L. 444-2b, whereas in most $A u$. afarensis mandibles the position of the $\mathrm{P}_{4} \mathrm{~S}$ is anterior to the postero-inferior edge of the symphysis. Au. afarensis specimens such as A.L. 207-13 and A.L. 266-1 show that the $\mathrm{P}_{4} \mathrm{~S}$ are set at the posterior-most margin of the symphysis. The extramolar sulcus (buccinator groove) of NFR-VP-1/29 cannot be accurately measured because the anterior edges of the ascending rami on both sides are broken, but it appears to be narrower than in most Au. afarensis mandibles (e.g., A.L. 438-1g, A.L. 444-2b, A.L. 128-23, and A.L. 266-1; White and Johanson, 1982; Kimbel et al., 2004). 
Lateral aspect The corpus is deep anteriorly and narrows posteriorly due to the superior angulation of the corpus base. This is characteristic of most Au. afarensis mandibles (Kimbel et al., 2004). When viewed laterally, a weak Curve of Spee is noticeable along the postcanine tooth row (see Fig. 2C-D). The symphysis is angled postero-inferiorly for its superior half but rounded and bulbous at its base as in most Au. afarensis mandibles such as A.L. 400-1a (White and Johanson, 1982) but more receding than the geologically younger mandibles such as A.L. 288-1, A.L. 444-2b and A.L. 438-1g (Kimbel et al., 2004; see Figs. 7 and 8). It approaches L.H.-4 in its basal symphyseal morphology by the fact that its inferior torus extends more posteriorly than the superior torus. However, it is not as 'cut away' as in L.H.-4 (Fig. 8). The lateral prominence is not as robust as $A u$. afarensis specimens such as A.L. 444-2b and A.L. 438-1g, but it shows noticeable bilateral asymmetry. The expression of the prominence on the left side starts at the base of the origin of the ascending ramus and sweeps antero-inferiorly as a ridge-like structure terminating at the $\mathrm{M}_{1}$ level. This expression is absent on the right side. The root of the ascending ramus begins at mid- $\mathrm{M}_{2}$. Although the root of the ascending ramus is broken on both sides, it appears that it would have obscured most of the $\mathrm{M}_{3}$. The lateral corpus hollow is bounded superiorly by the lateral prominence, antero-inferiorly by the $\mathrm{P}_{3}$ jugum and a prominent ridge that runs postero-inferiorly from the base of the $\mathrm{P}_{3}$ jugum to the corpus base ending at the $\mathrm{M}_{1}$ level and postero-inferiorly by the well-defined oblique line that emanates from the lateral prominence and runs antero-inferiorly to terminate at the corpus base at $\mathrm{M}_{1}$ level. This gives the lateral corpus contour hollow on the left side an inverted triangular shape. A small depression is present between the canine and the $\mathrm{P}_{3}$ close to the alveolar margin. The extramolar sulcus is narrow (estimated to ca. 6-7 $\mathrm{mm}$ at the base of the ascending ramus between $\mathrm{M}_{2}$ and $\mathrm{M}_{3}$ ) relative to the corpus breadth at the base of the root of the ramus. The origin of the ascending ramus is 
robust medio-laterally. Numerous platysmatic striae are present along the horizontal length of the corpus, particularly close to its base. These striae are mostly located below the main mental foramina and oriented postero-inferiorly. These striae have also been documented in $A u$. afarensis specimens such as A.L. 288-1, MAK-VP-1/2, and MAK-VP-1/12 (Johanson et al., 1982c; White et al., 2000).

There are multiple mental foramina on both sides of the mandible. The main mental foramen $(2.5 \mathrm{~mm} \times 2.5 \mathrm{~mm})$ on the left side is situated at $\mathrm{P}_{3} / \mathrm{P}_{4}$ level slightly below mid-corpus height. This foramen opens antero-superiorly. A second, slightly smaller foramen (1.8 mm x 1.6 $\mathrm{mm}$ ), is situated about two-thirds down the corpus height at mesial $\mathrm{M}_{1}$ level. This foramen opens infero-posteriorly. At least three accessory foramina of variable size are visible on the left side. The main mental foramen on the right side (4.2 $\mathrm{mm} \mathrm{AP}$ and $2.6 \mathrm{~mm} \mathrm{SI})$ is situated at $\mathrm{P}_{4}$ level slightly below mid-corpus height and opens antero-superiorly. The exit of the foramen is deeply furrowed forming an antero-posteriorly oriented groove about $4.5 \mathrm{~mm}$ long. There are two accessory foramina: one close to the alveolar margin at $\mathrm{P}_{3} / \mathrm{P}_{4}$ and a second located $7 \mathrm{~mm}$ posterior to the main mental foramen.

Medial aspect The alveolar margin, where intact, such as on the right side between $\mathrm{M}_{1}$ and $\mathrm{M}_{3}$, is relatively sharp and less rounded. The alveolar prominence is strong particularly anteriorly below $\mathrm{P}_{3}-\mathrm{M}_{1}$. Corpus contour seems to have been interrupted by root jugum at the mesial $\mathrm{M}_{1}$ root level on both sides. The anterior and posterior subalveolar fossae are clearly defined. The anterior subalveolar fossa is shallow, positioned at mid-corpus height, and sweeps anteroinferiorly from mesial $\mathrm{M}_{1}$ to mid- $\mathrm{M}_{2}$ level. The posterior alveolar fossa is deeper and wider and sweeps anteroinferiorly starting from the base at mid $\mathrm{M}_{2}$ level to mid-corpus at distal $\mathrm{M}_{3}$ level. The two fossae are separated by an anteroinferiorly sweeping ridge-like eminence. Posteriorly, 
close to the broken gonial angle, a well-developed crest runs from the base of the corpus at distal $\mathrm{M}_{2}$ level superiorly and then inferoposteriorly to the basally concave base of the corpus near the gonial angle. This crest probably marks the insertion for the anterior portion of the medial pterygoid muscle. The mylohyoid line is poorly defined. However, the mylohyoid groove is relatively deep and extends anteroinferiorly down to the posterior end of the lateral corpus at distal $\mathrm{M}_{3}$. The base of the ascending ramus is clearly separated from the lateral corpus. Anterior symphyseal region In lateral view, the symphysis slope is comparable to most $A u$. afarensis specimens. However, the basal half slopes more, comparable to L.H.-4. Incisal incisura are present immediately below the $\mathrm{I}_{2}$ alveolar margins. These incisura allow the formation of two vertical ridges (juga) starting from midline level and going all the way to the alveolar margin between the first incisors. There is a palpable eminence at the position of the symphyseal tuber. In superior view, the shape of the symphysis tends to be flat rather than a gentle curve. The canine jugum, partially preserved on the right side, is strong and visible anteriorly.

Posterior symphyseal region The postincisive planum is posteriorly concave both transversely and superoinferiorly. However, it is both transversely and superoinferiorly narrower than $A u$. afarensis specimens such as A.L. 400-1a, and MAK-VP-1/12. The planum is short and less steep superoinferiorly. The transverse narrowness is largely due to the strong transverse torus/alveolar prominence at the $\mathrm{P}_{3}-\mathrm{M}_{1}$ level. Otherwise, NFR is bilaterally wider at $\mathrm{C} / \mathrm{P}_{3}$ level than most Au. afarensis specimens. A well-developed superior transverse torus marks the superior border of the deep digastric fossa. The inferior transverse torus at midline is as thick as its superior counterpart and extends more posteriorly than the superior transverse torus. This gives the basal half of the symphysis a more receding appearance. This is in some ways similar 
to L.H.-4 although it is not as "cut-away" as the latter. The fossa is larger than in A.L. 400-1a. It is divided into two chambers by a rounded bony septum. The supraspinous foramen is situated at midline at the end of the bony septum dividing the two digastric fossae chambers. There is no visible mental spine here.

Basal aspect The corpus base is almost evenly thick starting from the posterior end of the digastric fossae (Fig. 2B). The basal margin is rounded for the most part and slightly everted posteriorly. The digastric fossae are shallow but well defined. Immediately posterior to the digastric fossae, there are strong crests (prominent on the left side) along the base of the corpus marking the insertion for the anterior part of the mylohyoid muscles. These crests continue posteriorly all the way to the level of the third molar. They sweep superiorly and then inferiorly at the level of $\mathrm{M}_{2}$ and $\mathrm{M}_{3}$. Anterior to the broken gonial angle on the left side, there are welldeveloped tubercles on both the medial and lateral sides.

Symphyseal cross-section The shape and inclination of the NFR-VP-1/29 symphysis is comparable to $A u$. afarensis specimens such as MAK-VP-1/12, A.L. 400-1a, and A.L. 333w-60 (White et al., 2000; Kimbel et al., 2004) (Figs. 7 and 8). It is more receding than almost all of the Au. afarensis mandibles from the upper part of the Kada Hadar Member (e.g., A.L. 417-1a, A.L. 437-1, A.L. 437-2, 438-1g, and A.L. 444-2; see Figs. 7 and 8).

Mandibular cross section at $\mathrm{M}_{1}$ A coronal section of NFR-VP-1/29 at the $\mathrm{M}_{1}$ level shows that it is most similar to A.L. $333 \mathrm{w}-60$ and to some degree to MAK-VP-1/12, in terms of having a welldeveloped superior transverse torus compared to the inferior transverse torus. However, the lateral wall of NFR-VP-1/29 is more vertical than those of these two specimens, and more like A.L. 198-1 (see Figure 5.31 in Kimbel et al., 2004 and Fig. 9 here). The mandibular corpus shape index ((breadth/height) $* 100)$ of NFR-VP-1/29 is $58.4 \%$ on the right side and $61.2 \%$ on the left 
side with an average of $59.8 \%$ (see Table 5 for measurements). The average index is identical to A.L. 438-1, whereas the index on the right side is similar to specimens such as A.L. $333 \mathrm{w}-$ 32+60, MAK-VP-1/12, and L.H.-4 (Kimbel et al., 2004). In general, the average index is slightly larger than the mean for Au. afarensis but within 1 standard deviation of all known Au. afarensis mandibles (see Kimbel et al., 2004 for further discussions).

Internal corpus anatomy The cortex is thickest at the corpus base and evenly thick on the lateral wall and at the inferior transverse torus. It is also relatively thick along the alveolar margin. However, cortical thickness at the superior transverse torus is extremely thin. This is also the case in Au. afarensis mandibles such as A.L. 277-1 (White and Johanson, 1982). The central part of the corpus is mostly filled with trabecular bone, and in some areas hollow, but gets denser in the peripheral areas. Coronal section between the $\mathrm{P}_{4}$ and $\mathrm{M}_{1}$ shows that the corpus on the right side is filled with trabeculae more than the left side although the significance or reason for the bilateral asymmetry requires further investigation.

Dentition The crowns of the anterior teeth $\left(\mathrm{I}_{1}-\mathrm{P}_{3}\right)$ of NFR-VP-1/29, except for the left $\mathrm{I}_{2}$ crown, which was found isolated, are missing, with only their roots preserved on both sides. The $\mathrm{P}_{4}-\mathrm{M}_{3}$ row on the left side is preserved intact. The same is true for the right side except for the buccal half of the $\mathrm{M}_{1}$, which is broken off. All preserved teeth show no sign of surface weathering or other biotic and/or abiotic alterations although wear in some of the teeth has minimally obliterated occlusal morphology. Measurements are provided in Table 6.

The left $\mathrm{I}_{2}$ crown was recovered isolated from the jaw. The crown is intact, with a clean break at the CEJ. The mesial half of the incisal edge is slightly more worn than the distal half. It has dentine exposed across the entire occlusal surface with a slight tilt lingually. Its overall shape and morphology is similar to Au. afarensis $\mathrm{I}_{2} \mathrm{~s}$ (Kimbel et al., 2004). The MD of the crown flares 
from the cervix $(4.2 \mathrm{~mm})$ up to the occlusal surface $(6.6 \mathrm{~mm})$. The MD is close to the mean of Au. afarensis $(6.3 \mathrm{~mm} ; n=7)$. The $\mathrm{LaL}$ dimension at its base close to the CEJ is $8.4 \mathrm{~mm}$, slightly above the mean for $A u$. afarensis $(8.0 \mathrm{~mm})$. The labial face is SI flat but slightly convex labially. The lingual face is concave above the basal swelling and lacks any sign of vertical mesial and distal grooves, unlike Au. afarensis specimens such as A.L. 400-1a. However, its occlusal wear is almost identical with A.L. 400-1a, particularly in the distal half of the incisal edge being more worn than the medial half. The mesial IPF measures $2.6 \mathrm{~mm}$ SI and $2.5 \mathrm{~mm} \mathrm{LaL}$. The distal IPF is slight larger, measuring $2.8 \mathrm{~mm} \mathrm{SI}$ and $2.6 \mathrm{~mm} \mathrm{LaL}$.

The $\mathrm{P}_{4}$ crowns on both left and right sides are preserved intact. The right side is slightly more worn than the left side. However, they appear to be identical in their occlusal morphology. The description here is based on the less worn left side. The Med is placed more mesially than the Prd. The Prd occupies almost the entire buccal half of the crown, is worn flat, and has a small dentine exposure measuring $1.4 \mathrm{~mm}$ by $1.0 \mathrm{~mm}(1.6 \mathrm{~mm}$ by $1.0 \mathrm{~mm}$ on the right side). The $\mathrm{Fa}$ is obliterated by wear and only a small pit (small slit-like groove on the right side) is visible as a remnant of the Fa. However, the Mmr appears to have been thick. The Fp is positioned slightly lower (closer to the root) and more lingually than the Fa. When viewed mesially or distally, the buccal face slightly slopes occlusally, whereas the lingual face is vertical. In lateral view, it has a shallow vertical groove on its distobuccal corner that gets wider from its base toward the occlusal surface. In mesial view, the IPF is set high, close to the occlusal rim and measures 4.5 BL and 2.7 SI. Summary statistics of dental crown size and shape for early Australopithecus taxa and NFR are provided in Table 7.

In terms of premolar root morphology, the $\mathrm{P}_{3} \mathrm{~s}$ of NFR-VP-1/29 have a mesiobuccally positioned circular root with a single root canal and a plate-like distal root with two root canals 
that converge distally (Fig. 10). The $\mathrm{P}_{4} \mathrm{~S}$ have two BL elongated plate-like roots for most of the root length below the crown base and each root has two root canals. The distal root is positioned more lingually than the mesial counterpart and it is also slightly larger. Each root has two root canals and the distal root bifurcates close to the tip of the root.

The $\mathrm{M}_{1}$ crown is intact on the left side, whereas the buccal half is missing on the right side. Therefore, the description is based on the left side. The crown is a MD long rectangle with rounded corners. Both of the lingual and buccal faces are mildly bilobate. The Prd, Med, and Hyd are of comparable size. The End is smaller and almost the same size as the Hld. The Fa, Fc, and Fp are obliterated by wear. The Prd and Hyd are worn flat and have centrally positioned rounded dentine pits. The pit on the Prd has a diameter of $1.9 \mathrm{~mm}$. The one on the Hyd measures $1.2 \mathrm{~mm}$. The Med and End tips are polished by wear but with no dentine exposure. These two cusps are separated by a transverse groove that extended to the lingual wall, also dividing them half way on the lingual side. The Hld is worn flat but with no dentine exposure. It is separated from the Hyd by a small groove located on the disto-buccal corner closer to the occlusal rim.

Both left and right $\mathrm{M}_{2}$ crowns are preserved intact. The occlusal outline is a mesiodistally elongated rectangle with rounded corners. All of the five major cusps are bounded by visible transverse and longitudinal grooves. The Prd is the largest cusp followed by (from largest to smallest) the Med, Hyd, End, and Hld. The Dmr is expressed more like C6 on the distolingual corner of the crown. The Fa is obliterated by wear and a deep longitudinal groove separates the Prd from the Med. The Prd and Hyd are separated by a deep transverse groove that extends all the way from the occlusal surface to the buccal wall of the crown. The Fc is deep and positioned more lingually. The small slit-like Fp is also positioned more lingually. A short shallow groove 
separates the Hyd from the Hld on the occlusal surface. The Med and End are higher than the other cusps. Their tips are worn flat but with no dentine exposure.

Both left and right $\mathrm{M}_{3}$ crowns are preserved intact. Although both crowns are almost identical in terms of their occlusal morphology, description is based on the left side for consistency. The occlusal outline is an MD elongate rectangle that tapers distally and ends in a rounded distal rim. All of the major cusps are bounded by well-developed grooves. The Prd is the largest in terms of its surface area, followed from largest to smallest by the Med, End, Hyd and Hld. The C6 is well developed and only slightly smaller than the Hld. The occlusal surface of the buccal cusps is polished by wear but with no dentine exposure. The apex of C6 also shows polishing on its tip. The Med and End are relatively high and show some polishing. The Fa is represented by two small dots on the lingual and buccal sides of the longitudinal groove that bounds the Prd and Med and ends at the mesial edge of the Fc. Two deep transverse grooves that extend to the buccal surface separate the Med, Hyd, and Hld from each other. Three grooves that separate the three distal cusps and the $\mathrm{C} 6$ from each other terminate in the centrally positioned relatively deep Fp. The lingual and buccal walls are trilobate and the buccal wall slightly tapers occlusally compared to the vertical lingual wall.

\section{NFR-VP-1/2: RM 1 (Fig. 2E)}

This specimen is a surface discovery and consists of a complete but unerupted crown. It is broken at the CEJ and it has no sign of wear on any of the cusps. Some enamel is chipped at the mesio-buccal corner close to the CEJ. Its occlusal outline is a MD elongate rectangle, slightly tapering distally with rounded angles. The Med is the largest. All of the other cusps, except the Hld, are subequal. A small C6 is present. The two lingual cusps are much higher than their buccal counterparts. All five major cusps are bounded by grooves. The Med and Prd are 
separated by a short longitudinal groove that emanates from the Fa. The Fa is a slit-like structure bound mesially by a well-defined Mmr. The grooves that separate all other cusps emanate from the slightly buccally positioned Fc and extend as deep grooves onto the lingual and buccal walls, extending all the way to the CEJ. The buccal and lingual walls are therefore trilobate and bilobate, respectively. A small inverted V-shaped Fp is bounded by the Hld, End and a C6.

\section{NFR-VP-1/58: RM $M_{2}$ or $R M_{3}$ (Fig. 2F)}

This specimen is a surface discovery and consists of a complete crown. It is broken at the CEJ. The buccal cusps are polished indicating that the crown was in occlusion, but it has no sign of dentine exposure. The Med is the largest cusp followed by the subequal Prd and Hyd. The Hld is the smallest. There is a small C6 distal to the End. All major cusps are separated by transverse and longitudinal grooves. The transverse groove separating the Prd from the Hyd and the Med from the End extend further into the buccal and lingual walls of the crown, making these walls bilobate. A number of secondary fissures run down from the Med and Prd toward the Mlg. The slit-like Fa is centrally positioned and mesially bounded by a well-defined $\mathrm{Mmr}(1.3 \mathrm{~mm})$. The Fc is positioned more lingually and manifested as the junction point for all the grooves that separate the major cusps. A tiny Fp that is positioned more lingually is present and bound by the End, Hld, and a tiny C6. The mesial IPF is concave mesially and measures $4.0 \mathrm{~mm}$ MD and 2.5 $\mathrm{mm}$ SI. There is no sign of a distal IPF and the distal wall is rounded. However, its dimensions best fit into the second molar distribution of Au. afarensis (see discussion below).

\section{NFR-VP-1/96: L/C fragment (not figured)}

This is an extremely worn lingual half of a lower canine. The entire preserved lengths of the crown and the root are $6.9 \mathrm{~mm}$ and $17.5 \mathrm{~mm}$, respectively. The crown is worn all the way to the level of the distal tubercle and none of its parts is preserved enough for detailed description. 


\section{NFR-VP-1/213: RM ${ }^{3}$ (Fig. 2G)}

This is a complete $\mathrm{M}^{3}$ crown with a small part of its root $(6.5 \mathrm{~mm}$ long below the protocone) preserved. A hairline crack runs longitudinally across the protocone and hypocone close to the lingual edge of the cusps. However, the occlusal morphology is not affected by the crack. It has premortem enamel chipping on the buccal wall of the paracone close to the occlusal rim. The occlusal outline is trapezoidal, tapering distally. All major cusps are polished by wear although no dentine is exposed on any of them. The paracone is slightly pointy compared to all other cusps. The protocone is the largest cusp followed by the paracone. The hypocone and metacone are smaller and subequal. A number of short lingual grooves are present on the protocone. The groove separating the protocone from the hypocone runs all the way down to the CEJ across the lingual wall. The Fa is obliterated by wear. A slit-like Fc runs from the lingual rim as a continuation of the central lingual groove and terminates between the paracone and the metacone. A small Fp is centrally positioned bounded by the small metacone and the Dmr. The IPF is $4.4 \mathrm{~mm} \mathrm{MD}$ and $1.4 \mathrm{~mm} \mathrm{BL}$. The crown is $12.2 \mathrm{~mm} \mathrm{MD} \mathrm{(12.7} \mathrm{mm} \mathrm{corrected} \mathrm{for} \mathrm{IPF)} \mathrm{and}$ 13.8 BL.

\section{NFR-VP-1/214: Frontal fragment (not figured)}

This is a small frontal fragment with dimensions of $22.5 \mathrm{~mm}$ by $22.2 \mathrm{~mm}$. Its fragmentary nature does not allow detailed description.

\section{Metric comparisons}

Metric analysis reinforces the assignment of the Nefuraytu mandible to Au. afarensis. The specimen shows postcanine megadontia and other heavy-mastication features that typify this species. Dentognathic dimensions fall within or very close to the range of variation documented by specimens from Hadar, Laetoli and Dikika (Fig. 11, Tables 5 and 6; see SOM D for the list of 
$A u$. anamensis and $A u$. afarensis specimens included in the comparative analysis). The large overall size of NFR-VP-1/29 suggests that it represents a male individual.

The NFR-VP-1/29 $\mathrm{P}_{4}$ crowns are most similar in size to large Au. afarensis specimens such as A.L. 582-11 and L.H.-3, and larger than any Au. anamensis $\mathrm{P}_{4} \mathrm{~s}$ known to date. They are further $A u$. afarensis-like in crown shape (Fig. 11A, Table 7), showing the distinct MD expansion that is absent in $A u$. anamensis (Ward, 2014). The NFR-VP-1/29 $\mathrm{P}_{4}$ crowns are not as large or MD-expanded as the KNM-WT $8556 \mathrm{P}_{4}$.

Au. afarensis tends to have larger $\mathrm{M}_{1}$ crowns than Au. anamensis $(\mathrm{t}=-2.6, p<0.05)$. The NFR-VP-1/29 $\mathrm{M}_{1}$ crown is among the largest known for Au. afarensis (second only to DIK-2-1) and it falls near the $A u$. afarensis mean for crown shape (Fig. 11B, Table 7). The isolated NFRVP-1/2 $\mathrm{M}_{1}$ crown falls at the $A u$. afarensis mean with regard to size, but is narrower than any other specimen in the comparative sample.

Other dental dimensions preserved in the Nefuraytu specimens do not differentiate species, but they fall within or very close to the known Au. afarensis range of variation (Fig. 11, Table 6). The $\mathrm{I}_{2}$ has MD and BL dimensions of $6.6 \mathrm{~mm}$ and $8.5 \mathrm{~mm}$, respectively. It is slightly above the mean for Au. afarensis ( $\mathrm{MD}=6.2 \mathrm{~mm}[n=5] ; \mathrm{BL}=8.0 \mathrm{~mm}[n=7]$ ). Its $\mathrm{BL}$ is closer to that of A.L. 444-2 $(8.8 \mathrm{~mm})$, the specimen that so far represents the upper limit for this dimension in the species (Kimbel et al., 2004). NFR-VP-1/29 $\mathrm{M}_{2} \mathrm{~S}$ are large, similar to A.L. 1881 and KNM-KP 30500 in crown size and shape. The isolated $\mathrm{M}_{2}$ NFR-VP-1/58 also falls close to the mean values of the $A u$. afarensis crown size and shape. NFR-VP-1/29 $\mathrm{M}_{3} \mathrm{~s}$ are large and similar to A.L. 620-1 and KNM-KP 47953 in crown size and shape. NFR-VP-1/213 (M $\left.{ }^{3}\right)$ falls within the range of both $\mathrm{Au}$. anamensis and Au. afarensis in terms of its MD and BL dimensions. It is almost identical to the Au. anamensis specimen (ARA-VP- 14/1) from the Middle Awash in 
both its MD and BL dimensions. It is also similar to the Au. afarensis specimen (A.L. 770-1a) from Hadar in its MD dimension although the Hadar specimen is much wider in its BL dimension. However, the shape of NFR-VP-1/213 falls outside the $95 \%$ confidence interval of Au. anamensis and falls at the lower end of Au. afarensis (Table 7).

The NFR-VP-1/29 mandibular corpus is large, most similar to geologically younger $A u$. afarensis specimens from the upper part of the Denen Dora Member (A.L. 333w-32+60) and the Kada Hadar Member (A.L. 437-1, A.L. 437-2, A.L. 438-1, and A.L. 444-2) (Fig. 11E-F). All of these Hadar mandibles are younger than 3.22 Ma (Kimbel et al., 2004; Campisano et al., 2007). It is also similar in size to the Dikika mandible (DIK-2-1), which was recovered from the Basal Member of the Hadar Formation below the 3.42 Ma Sidi Hakoma Tuff (Alemseged et al., 2005). The corpus shape ratio (=(breadth/height) $* 100)$ of NFR-VP-1/29 at the $\mathrm{M}_{1}$ level is 59.8 , almost identical to the mean of $23 \mathrm{Au}$. afarensis mandibles (58.2), and distinct from the broad corpora of the $A u$. deyiremeda mandibles. KNM-WT 8556 was described as robust and assigned to $A u$. afarensis (Brown et al., 2001). However, the corpus of this mandible is fairly similar to the NFR mandible in terms of corpus dimensions, but distinct from the broad mandibles of $A u$. deyiremeda. The corpus dimensions of the two mandibles assigned to Au. bahrelghazali (KT-12 and KT-40; Brunet et al. 1996; Guy et al. 2008) are unknown although the size of the $\mathrm{P}_{4}$ of KT 12 falls within the range of $A u$. afarensis (see Figure 11A).

\section{Temporal trends}

The NFR-VP-1/213 $\mathrm{M}^{3}$, assigned here to Australopithecus sp., falls very close to the size expected for Au. afarensis specimens dated to 3.3-3.2 Ma, corroborating the trend reported for this element (Lockwood et al., 2000). However, the dimensions of the NFR-VP-1/29 mandibular corpus are considerably larger than would be expected for its geological age, and a similar 
observation has been made for DIK-2-1 (Alemseged et al., 2005). The addition of these more recent specimens to the $A u$. afarensis hypodigm slightly alters the support for the temporal trend hypothesis, as concerns the mandibular corpus. Lockwood et al. (2000) reported a significant increase in mandible size over time for metrics considered (geometric mean of corpus height and breadth, corpus height independently and breadth independently). Using the methodology described by Lockwood et al. (2000), in which the Spearman rank correlation coefficient $\left(r_{\mathrm{s}}\right)$ is reported but the significance of the correlation is judged using a permutation test of the gamma statistic $\left(p_{\Gamma}\right)$, and an expanded sample that includes the Maka mandibles (MAK-VP-1/12, MAKVP-1/2; White et al., 2000), the Dikika mandible (DIK-2-1; Alemseged et al., 2005) and NFRVP-1/29, we found that the temporal trend in corpus size (as represented by the geometric mean of height and breadth) at the $\mathrm{M}_{1}$ level remains significant $\left(r_{s}=0.43, p_{\Gamma}<0.05\right)$, as does the trend in corpus height $\left(r_{s}=0.39, p_{\Gamma}<0.05\right)$. In contrast, the trend in corpus breadth drops below the level of significance (breadth $r_{s}=0.28, p_{\Gamma}=0.09$ ).

\section{Au. afarensis and Au.deyiremeda at Woranso-Mille}

Most of the differences that distinguish NFR-VP-1/29 from Au. deyiremeda are also differences that distinguish the latter from Au. afarensis (Fig. 12; see Haile-Selassie et al., 2015, for details). For example, Au. deyiremeda mandibles (BRT-VP-3/14 and WYT-VP-2/10) are especially broad for their overall small size (Fig. 11E-F). The ramus root is positioned more anteriorly than is typical for $A u$. afarensis, giving the Au. deyiremeda corpus cross section a more inflated appearance (Fig. 9). In contrast, NFR-VP-1/29 is a very large mandible but not especially broad - its corpus dimensions at all positions along the tooth row are representative of Au. afarensis. It also exhibits a typical Au. afarensis-like corpus cross-section (Fig. 9). 


\section{Discussion}

NFR-VP-1/29 is a large mandible, overlapping in its size with the geologically younger specimens of $A u$. afarensis from the Kada Hadar Member (e.g., A.L. 417-1, A.L. 437-1, A.L. 437-2, A.L. 438-1g, and A.L. 444-2). Morphologically, however, its symphysis is more sloping than these specimens and more similar to the geologically older specimens such as A.L. 330-5, A.L. 400-1a and MAK-VP-1/12 (White et al., 2000; Kimbel et al., 2004), while its corpus crosssection at $\mathrm{M}_{1}$ can easily be subsumed within the range of variation seen in Au. afarensis (Fig. 9). The development of the superior transverse torus of NFR-VP-1/29 is also best matched by A.L. $333 \mathrm{w}-32+60$. Overall, NFR-VP-1/29 retains almost all of the distinctive archaic features documented for $A u$. afarensis (Kimbel et al., 2004). These features include a posteriorly sloping symphysis, a low and rounded basally set inferior transverse torus, antero-superiorly opening mental foramen, a lateral corpus hollow bound anteriorly by the $\mathrm{C} / \mathrm{P}_{3}$ jugae and posteriorly by the lateral prominence, and ascending ramus arising posterior and high on the corpus (Johanson and White, 1979; White et al., 1981, 2000; Johanson et al., 1982c; Kimbel et al., 2004; Kimbel and Delezene, 2009). Its dentition also falls within the size range of Au. afarensis (see Table 6).

In addition to being one of the few well preserved mandibles of $A u$. afarensis, NFR-VP1/29 is also important in testing the hypothesis related to the temporal trend in Au. afarensis mandibular corpus size increase (Lockwood et al., 2000). Given its geological age and size, NFR-VP-1/29 might appear to counter the hypothesized temporal trend (Lockwood et al., 2000), in a similar way as DIK-2-1 (Alemseged et al., 2005). However, given the extensive size variation in $A u$. afarensis mandibles, NFR-VP-1/29 could yet be another large mandible from a horizon that is older than 3.2 Ma. As Alemseged et al. (2006) clearly noted, there are, for example, large and small Au. afarensis mandibles from a single horizon at Maka in the Middle 
Awash (White et al., 2000), which are dated to ca. 3.4 Ma and contemporaneous with DIK-2-1. Therefore, the presence of few large mandibles in older horizons does not necessarily falsify the observed trend that is inferred from a larger sample size (Lockwood et al., 2000).

Given the overall size of NFR-VP-1/29, which is comparable to specimens such as A.L. $333 \mathrm{w}-60$ from the Denen Dora Member ( $>3.2 \mathrm{Ma}$ ), it is possible to argue that mandibular corpus size increase in $A u$. afarensis might have started earlier than the Kada Hadar Member. Other mandibles from the Denen Dora Member, such as A.L. 487-1 and A.L. 620-1, are also relatively larger than the average-sized Au. afarensis mandibles. Dimensions of the isolated teeth from Nefuraytu are also above the average for the species in terms of their MD and BL dimensions even though they fall within the documented range of variation for the species.

NFR-VP-1/29 is contemporaneous with WYT-VP-2/10, one of the paratypes of $A u$. deyiremeda (Haile-Selassie et al., 2015). However, in addition to the metric differences described above, NFR-VP-1/29 is further distinguished from Au. deyiremeda in overall mandibular configuration. For example, Au. deyiremeda mandibles are distinguished from NFRVP-1/29 and other $A u$. afarensis mandibles by their more anteriorly positioned origin of the ascending ramus, relatively smaller teeth compared to corpus size, wide extramolar sulcus, BL inflated corpus at the level of the molars, and poorly developed lateral corpus hollow (HaileSelassie et al., 2015; See Fig. 12). Thus, despite its temporal and spatial proximity to $A u$. deyiremeda, NFR-VP-1/29 does not belong to the latter species and further confirms that there were at least two contemporaneous hominin species in the Woranso-Mille region during the middle Pliocene.

\section{Conclusion}


Hominin fossils from the Nefuraytu locality of the Woranso-Mille paleontological study area are chronologically placed between 3.330 Ma and 3.207 Ma. The hominin fossils from this locality include isolated teeth and a complete mandible with dentition (NFR-VP-1/29). Comparative analyses of these specimens show that they are metrically and morphologically indistinguishable from the well-known and contemporaneous species Au. afarensis. NFR-VP1/29 is most similar to specimens such as the 3.2 Ma A.L. 333 w- 60 from Hadar and $3.4 \mathrm{Ma}$ MAK-VP-1/12 from the Middle Awash and retains most of the primitive dentognathic features described for $A u$. afarensis. NFR-VP-1/29 is metrically and morphologically different from $A u$. deyiremeda and within the range of morphological and metric variation observed in $A u$. afarensis. Thus, although it was found in close temporal and spatial proximity with $A u$. deyiremeda, the morphological and metric evidence supports assignment of the Nefuraytu hominins to $A u$. afarensis. This is significant for two major reasons. First, the NFR specimens assigned to $A u$. afarensis and the KSD-VP-1/1 partial skeleton (Haile-Selassie et al., 2010b) sample the northernmost occurrence of the species thus far known in the fossil record of eastern Africa. Second, they clearly indicate that $A u$. afarensis at Woranso-Mille was living in close proximity with other related hominin taxa, such as the species represented by the Burtele foot (BRT-VP-2/73; Haile-Selassie et al., 2012) and Au. deyiremeda (Haile-Selassie et al., 2015). The Woranso-Mille study area has yielded a number of middle Pliocene fossil hominin remains ranging in age from ca. 3.0 Ma to $>3.8 \mathrm{Ma}$. The fossil remains from the study area appear to represent multiple hominin taxa, sometimes overlapping not only in time but also in space. The presence of cf. Au. anamensis at $>3.7 \mathrm{Ma}$ (Haile-Selassie, 2010), Au. afarensis at 3.6 Ma (Haile-Selassie et al., 2010b) and 3.3-3.2 Ma, the Burtele foot at 3.4-3.3 Ma (Haile-Selassie et al., 2012), and the recently named 3.5-3.3 Ma Au. deyiremeda (Haile-Selassie et al., 2015) at 
Woranso-Mille are all clear evidence that there were multiple contemporaneous hominin species in eastern Africa during the middle Pliocene. Analyses of associated faunal assemblages, stable carbon isotope data from fossil teeth and pedogenic carbonates indicate that these hominins were living in mixed $\mathrm{C}_{3}-\mathrm{C}_{4}$ to $\mathrm{C}_{3}$-dominated landscapes at Woranso-Mille.

Finally, whereas the recovery of more fossils representing the newly named middle

Pliocene hominin taxa from eastern and central Africa (Brunet et al., 1996; Leakey et al., 2001; Haile-Selassie et al., 2015), and a better understanding of their paleobiology is of paramount importance to test the hypothesis that multiple related hominin taxa lived contemporaneously, and at times in close proximity, instant predilections for subsuming some or all of the named middle Pliocene hominin species to $A u$. afarensis without credible evidence is clearly unwarranted. Only the recovery of more complete fossils will clarify these issues.

\section{Acknowledgments}

The authors would like to thank the Authority for Research and Conservation of Cultural Heritage, Ministry of Culture and Tourism of the Ethiopian government and the Afar Regional State of Ethiopia for permission to conduct field and laboratory research; the Afar people of the Woranso-Mille area for their support in the field; Roger Mundry for statistical program; and William H. Kimbel for access to the original specimens of Au. afarensis. We would like to also thank Ahmed Elema for finding the Nefuraytu mandible and all those who were involved in its recovery. Comments from two anonymous reviewers and those of editor Dr. Mike Plavcan greatly improved the manuscript. This research was supported by grants from the National Science Foundation (BCS-0234320, BCS-0321893, BCS-0542037 and BCS-1124705), L.S.B. Leakey Foundation, the National Geographic Society, and the Cleveland Museum of Natural 
History. AD would like to acknowledge support from the National Science Foundation (award \#s 1322017 and 1125157). 


\section{References Cited}

Alemseged, Z., Wynn, J.G., Kimbel, W.H., Reed, D., Geraads, D., Bobe, R., 2005. A new hominin from the Basal Member of the Hadar Formation, Dikika, Ethiopia, and its geological context. J. Hum. Evol. 49, 499-514.

Alemseged, Z., Spoor, F., Kimbel, W.H., Bobe, R., Geraads, D., Reed, D., Wynn, J.G., 2006. A juvenile early hominin skeleton from Dikika, Ethiopia. Nature 443, 296-301.

Brown, B., Brown, F.H., Walker, A., 2001. New hominids from the Lake Turkana basin, Kenya. J. Hum. Evol. 41, 29-44.

Brunet, M., Beauvilain, A., Coppens, Y., Heintz, E., Moutayi, A.H.E., Pilbeam, D., 1996. Australopithecus bahrelghazali, une nouvelle espèce d'Hominidé ancient de la région de Koro Toro (Tchad). C. R. Acad. Sci. Paris Serie II 322, 907-913.

Campisano, C.J., 2007. Tephrostratigraphy and hominin paleoenvironments of the Hadar Formation, Afar Depression, Ethiopia. Ph.D. Dissertation, Rutgers, The State University of New Jersey.

Deino, A., Scott, G., Saylor, B., Alene, M., Angelini, J.D., Haile-Selassie, Y., 2010. ${ }^{40} \mathrm{Ar} /{ }^{39} \mathrm{Ar}$ dating, paleomagnetism, and tephrochemistry of Pliocene strata of the hominid-bearing Woranso-Mille area, west-central Afar Rift, Ethiopia. J. Hum. Evol. 58, 111-126.

Dupont-Nivet, G., Sier, M., Campisano, C.J., Arrowsmith, J R., DiMaggio, E., Reed, K., Lockwood, C., Franke, C., Hüsing, S., 2008. Magnetostratigraphy of the eastern Hadar Basin (Ledi-Geraru research area, Ethiopia) and implications for hominin paleoenvironments. In: Quade, J., Wynn, J.G. (Eds.), The Geology of Early Humans in the Horn of Africa. Geological Society of America Special Paper 446, 67-85. 
Green, D.J., Alemseged, Z., 2013. Australopithecus afarensis scapular ontogeny, function, and the role of climbing in human evolution. Science 338, 514-517.

Haile-Selassie, Y., 2010. Phylogeny of early Australopithecus: new fossil evidence from the Woranso-Mille (Central Afar, Ethiopia). Phil. Trans. R. Soc. B. 365, 3323-3331.

Haile-Selassie, Y., Deino, A., Saylor, B., Umer, M., Latimer, B., 2007. Preliminary geology and paleontology of new hominid-bearing Pliocene localities in the central Afar region of Ethiopia. Anthropol. Sci. 115, 215-222.

Haile-Selassie, Y., Saylor, B.Z., Deino, A., Alene, M., Latimer, B.M., 2010a. New hominid fossils from Woranso-Mille (Central Afar, Ethiopia) and taxonomy of early Australopithecus. Am. J. Phys. Anthropol. 141, 406-417.

Haile-Selassie, Y., Latimer, B.M., Alene, M., Deino, A., Gibert, L., Melillo, S.M., Saylor, B.Z., Scott, G.R., Lovejoy, C.O., 2010b. An early Australopithecus afarensis postcranium from Woranso-Mille, Ethiopia. Proc. Natl. Acad. Sci. 107, 12121-12126.

Haile-Selassie, Y., Saylor, B.Z., Deino, A., Levin, N.E., Alene, M., Latimer, B., 2012. A new hominin foot from Ethiopia shows multiple Pliocene bipedal adaptations. Nature 483, 565-569.

Haile-Selassie, Y., Gibert, L., Melillo, S., Ryan, T.M., Alene, M., Deino, A., Levin, N.E., Scott, G., Saylor, B.Z., 2015. New species from Ethiopia further expands middle Pliocene hominin diversity. Nature 521, 125-129.

Harrison, T., 2011. Hominins from the Upper Laetolil and Upper Ndolanya Beds, Laetoli. In: Harrison, T. (Ed.), Paleontology and Geology of Laetoli: Human Evolution in Context. Volume 2: Fossil Hominins and the Associated Fauna. Vertebrate Paleobiology and Paleoanthropology Series: Springer, New York, pp. 141-188. 
Johanson, D.C., Taieb, M., 1976. Plio-Pleistocene hominid discoveries in Hadar, Ethiopia. Nature 260, 293-297.

Johanson, D.C., White, T.D., 1979. A systematic assessment of early African hominids. Science 203, 321-330.

Johanson D.C., White T.D., Coppens Y., 1978a. A new species of the genus Australopithecus (Primates: Hominidae) from the Pliocene of eastern Africa. Kirtlandia 28, 1-14.

Johanson, D.C., Taieb, M., Gray, B.T., Coppens, Y., 1978b. Geological framework of the Pliocene Hadar Formation (Afar, Ethiopia) with notes on paleontology including hominids. In: Bishop, W.W. (Ed.), Geological Background to Fossil Man. Scottish Academic Press, Edinburgh, pp. 549-564.

Johanson, D.C., Taieb, M., Coppens, Y., 1982a. Pliocene hominids from the Hadar Formation, Ethiopia (1973-1977): Stratigraphic, chronologic, and paleoenvironmental contexts, with notes on hominid morphology and systematics. Am. J. Phys. Anthropol. 57, 373-402.

Johanson, D.C., White, T.D., Coppens, Y., 1982b. Dental remains from the Hadar Formation, Ethiopia: 1974-1977 collections. Am. J. Phys. Anthropol. 57, 545-603.

Johanson, D.C., Lovejoy, C.O., Kimbel, W.H., White, T.D., Ward, S.C., Bush, M.E., Latimer, B.M., Coppens, Y., 1982c. Morphology of the Pliocene partial hominid skeleton (A.L. 288-1) from the Hadar Formation. Am. J. Phys. Anthropol. 57, 403-451.

Kalb, J.E., 2001. Adventures in the Bone Trade: The Race to Discover Human Ancestors in Ethiopia's Afar Depression. Copernicus Books, New York.

Kimbel, W.H., Delezene, L.K., 2009. "Lucy” redux: a review of research on Australopithecus afarensis. Yearb. Phys. Anthropol. 52, 2-48.

Kimbel, W.H., White, T.D., 1988. Variation, sexual dimorphism and the taxonomy of 
Australopithecus. In: Grine, F.E. (Ed.), Evolutionary History of the "Robust" Australopithecines. Aldine de Gruyter, New York, pp. 175-192).

Kimbel, W.H., White, T.D., Johanson, D.C., 1985. Craniodental morphology of the hominids from Hadar and Laetoli: evidence of "Paranthropus" and Homo in the Mid-Pliocene of eastern Africa. In: Delson, E. (Ed.), Ancestors: The Hard Evidence. Liss, New York, pp. $120-137$.

Kimbel, W.H., Johanson, D.C., Rak, Y., 1994. The first skull and other new discoveries of Australopithecus afarensis at Hadar, Ethiopia. Nature 368, 449-451.

Kimbel, W.H., Rak, Y., Johanson, D.C., 2004. The Skull of Australopithecus afarensis. Oxford University Press, New York.

Kuiper, K.F., Deino, A., Hilgen, F.J., Krijgsman, W., Renne, P.R., Wijbrans, J.R., 2008. Synchronizing rock clocks of earth history. Science 320, 500-504.

Leakey, M.G., Feibel, C.S., McDougall, I., Walker, A., 1995. New four-million-year-old hominid species from Kanapoi and Allia Bay, Kenya. Nature 376, 565-571.

Leakey, M.G., Feibel, C.S., McDougall, I., Ward, C., Walker, A., 1998. New specimens and confirmation of an early age for Australopithecus anamensis. Nature 393, 62-66.

Leakey, M.G., Spoor. F., Brown, F.H., Gathogo, P.N., Kiarie, C., Leakey, L.N., McDougall, I., 2001. New hominin genus from eastern Africa shows diverse middle Pliocene lineages. Nature 410, 433-440.

Lee, J.-Y., Marti, K., Severinghaus, J.P., Kawamura, K., Yoo, H.-S., Lee, J.B., Kim, J.S., 2006. A redetermination of the isotopic abundances of atmospheric Ar. Geochim. Cosmochim. Ac. $70,4507-4512$. 
Levin N.E., Haile-Selassie, Y., Frost, S.R., Saylor, B.Z., 2015. Dietary change among hominins and cercopithecids in Ethiopia during the Early Pliocene. Proc. Nat. Acad. Sci. 112, $12304-12309$.

Lockwood, C.A., Richmond, B.G., Jungers, W.L., Kimbel, W.H., 1996. Randomization procedures and sexual dimorphism in Australopithecus afarensis. J. Hum. Evol. 31, $537-$ 548.

Lockwood, C.A., Kimbel, W.H., Johanson, D.C., 2000. Temporal trends and metric variation in the mandibles and dentition of Australopithecus afarensis. J. Hum. Evol. 39, 23-55.

Lourens, L., Hilgen, F., Shackleton, N.J., Laskar, J., Wilson, D. 2004., The Neogene Period. In: Gradstein, F., Ogg, J.G., Smith, G. (Eds.), A Geologic Time Scale. Cambridge University Press, Cambridge, pp. 409-440.

Mbua, E., Kusaka, S., Kunimatsu, Y., Geraads, D., Sawada, Y., Brown, F.H., Sakai, T., Boisserie, J-R., Saneyoshi, M., Omuombo, C., Muteti, S., Hirata, T., Hayashida, A., Iwano, H., Danhara, T., Bobe, R., Jicha, B., Nakatsukasa, M., 2016. Kantis: A new Australopithecus site on the shoulders of the Rift Valley near Nairobi, Kenya. J. Hum. Evol. 94, 28-44.

Melillo, S.M., 2011. Anatomy of the Australopithecus scapula and evolution of the human shoulder: Insights from a new fossil specimen, KSD-VP-1/1G. Ph.D. Dissertation, Stanford University.

Melillo, S.M., 2016. The shoulder girdle of KSD-VP-1/1. In: Haile-Selassie, Y., Su, D.F. (Eds.), The Postcranial Anatomy of Australopithecus afarensis: New Insights from KSD-VP-1/1. Springer, New York, pp. 113-141.

Reed, K.E., 2008. Paleoecological patterns at the Hadar hominin site, Afar Regional State, 
Ethiopia. J. Hum. Evol. 54, 743-768.

Reed, K.E., Bibi, F., 2011. Fossil Tragelaphini (Artiodactyla:Bovidae) from the Late Pliocene Hadar Formation, Afar Regional State, Ethiopia. J. Mammal. Evol. 18, 57-69.

Saylor, B.Z., Alene, M.A., Deino, A., Gibert, L., Haile-Selassie, Y., Melillo, S.M., Scott, G., 2016a. The geologic context of Korsi Dora and the partial skeleton KSD-VP-1/1. In: Haile-Selassie, Y., Su, D.F. (Eds.), The Postcranial Anatomy of Australopithecus afarensis: New Insights from KSD-VP-1/1. Springer, New York, pp. 13-23.

Saylor, B.Z., Angelini, J., Deino, A., Alene, M.A., Fournelle, J.H., Haile-Selassie, Y., $2016 b$. Tephrostratigraphy of the Waki-Mille area of the Woranso-Mille Paleoanthropological Research Project, Afar, Ethiopia. J. Hum. Evol. 93, 25-45.

Steiger, R.H., Jäger, E., 1977. Subcommission on geochronology: conventions on the use of decay constants in geo- and cosmochronology. Earth Planet. Sci. Lett. 36, 359-362.

Taieb, M., Johanson, D.C., Coppens, Y., Aronson, J.L., 1976. Geological and palaeontological background of Hadar hominid site, Afar, Ethiopia. Nature 260, 289-293.

Ward, C.V., 2014. Taxonomic affinity of the Pliocene hominin fossils from Fejej, Ethiopia. J. Hum. Evol. 73, 98-102.

Ward, C.V., Leakey, M.D., Walker, A., 2001. Morphology of Australopithecus anamensis from Kanapoi and Allia Bay, Kenya. J. Hum. Evol. 41, 255-368.

White, T.D., Johanson, D.C., 1982. Pliocene hominid mandibles from the Hadar Formation, Ethiopia: 1974-1977 collections. Am. J. Phys. Anthropol. 57, 501-544.

White, T.D., Johanson, D.C., Kimbel, W.H., 1981. Australopithecus africanus: its phyletic position reconsidered. S. Afr. J. Sci. 77, 445-470. 
White, T.D., Suwa, G., Hart, W.K., Walter, R.C., WoldeGabriel, G., de Heinzelin, J., Clark, J.D., Asfaw, B., Vrba, E., 1993. New discoveries of Australopithecus at Maka in Ethiopia. Nature 366, 261-265.

White, T.D., Suwa, G., Simpson S.W., Asfaw, B., 2000. Jaws and teeth of Australopithecus afarensis from Maka, Middle Awash, Ethiopia. Am. J. Phys. Anthropol. 111, 45-68.

White, T.D., WoldeGabriel, G., Asfaw, B., Ambrose, S., Beyene, Y., Bernor, R.L., Boisserie, JR., Currie, B., Gilbert, W.H., Haile-Selassie, Y., Hart, W.K., Hlusko, L.J., Howell, F.C., Kono, R.T., Lehmann, T., Louchart, A., Lovejoy, O.C., Renne, P.R., Saegusa, H., Vrba, E.S., Wesselman, H., Suwa, G., 2006. Asa Issie, Aramis and the origin of Australopithecus. Nature 440, 883-889. 


\section{Figure Captions}

Figure 1. A geological map showing the location and lithology of the Burtele-Nefuraytu (BRTNFR) localities within the Woranso-Mille study area. The image below shows a panoramic view of the fossiliferous sediments at Nefuraytu.

Figure 2. Nefuraytu (NFR) hominins. Occlusal (A), basal (B), right lateral (C), and left lateral (D) views of NFR-VP-1/29; Oclusal views of NFR-VP-1/2 (E), NFR-VP-1/58 (F), NFR$\mathrm{VP}-1 / 213(\mathrm{G})$.

Figure 3: Stratigraphic correlation between Nefuraytu and Burtele areas showing the inferred position of the Nefuraytu strata above those at Burtele (located $4 \mathrm{~km}$ to the west). The figure shows the stratigraphic position of a dated tuff at Burtele (Haile-Selassie et al., 2012, 2015), paleomagnetic and soil carbonate samples from Nefuraytu (Levin et al., 2015), and sandstones beds with in-situ vertebrate fossils. Black bars and white bars adjacent to sections indicate normal $(\mathrm{N})$ and reversed $(\mathrm{R})$ polarity, respectively. A composite N-R-N polarity sequence is tentatively correlated with the Astronomically tuned Neogene Time Scale (ATNTS) from Lourens et al. (2004). The stratigraphic position, paleomagnetic directions and available ${ }^{40} \mathrm{Ar} /{ }^{39} \mathrm{Ar}$ and $\mathrm{U} / \mathrm{Pb}$ age constrain the age of the Nefuraytu fossils to between 3.330 and 3.207 Ma. All geographic coordinates are listed using the WGS-84 Datum. The stereoplot shows the primary paleomagnetic directions for the Nefuraytu stratigraphic succession after AF and thermal demagnetization. Reverse polarity is shown for most samples with a mean direction of $176^{\circ} /-20^{\circ}$. Only one sample located $3 \mathrm{~m}$ below the top of the section shows evidence for normal polarity, the inclination of this sample is still negative probably because the secondary magnetization has not been completely removed. Stereographic projection 
referenced to magnetic north (declination $2^{\circ} \mathrm{E}$ ), with solid symbols on lower hemisphere (+ inclination) and open symbols on upper hemisphere (- inclination).

Figure 4: Age probability-density spectra of single-crystal ${ }^{40} \mathrm{Ar} /{ }^{39} \mathrm{Ar}$ dating results for pumice tuff samples WM07/N-1 and WM07/N-2 (bottom-most plot), above which are plotted several corresponding derived parameters (ranked age, moles ${ }^{39} \mathrm{Ar}, \mathrm{Ca} / \mathrm{K}$ ratio, and ${ }^{40}{ }^{40} \mathrm{Ar}$, the percent radiogenic ${ }^{40} \mathrm{Ar}$ ). The inset graph shows a subset of the analyses inferred to best define or constrain the emplacement age of the tuffs, with weighted-mean ages. All errors are shown at $1 \sigma$.

Figure 5. Three-dimensional total $\mathrm{Pb} / \mathrm{U}$ isochron diagram (Ludwig, 2009) of six zircon analyses from sample $\mathrm{WM} 12 / \mathrm{N}-1$. The ${ }^{204} \mathrm{~Pb} /{ }^{206} \mathrm{~Pb}$ axis, which is not shown, lies perpendicular to the plane of the plot.

Figure 6. Occlusal views of $A u$. afarensis mandibles. A) A.L. 288-1n; B) MAK-VP-1/12 (Image courtesy of Tim White); C) A.L. 400-1a; D) NFR-VP-1/29. Scale bar is $2 \mathrm{~cm}$.

Figure 7. Outline of symphyseal cross section of some Au. afarensis mandibles from Hadar, Middle Awash, and Laetoli (top and middle row) compared to Au. afarensis (NFR-VP1/29) and Au. deyiremeda (BRT-VP-3/14 and WYT-VP-2/10) mandibles from the Woranso-Mille (bottom row). Note that NFR-VP-1/29 is most similar to MAK-VP-1/12 while the Mandibles of $A u$. deyiremeda appear to be different from those of $A u$. afarensis in variable ways. The cross sections of $A u$. afarensis mandibles are modified from Kimbel et al.'s (2004) Figure 5.29 which was compiled from cross sections published in White et al., 2000; Brunet et al., 1996; and Ward et al., 2001. All outlines are not to scale. 
Figure 8. Right lateral views of $A u$. afarensis mandibles. A) A.L. 288-1n; B) A.L. 444-2b; C) MAK-VP-1/12 (Image courtesy of Tim White); D) NFR-VP-1/29; E) A.L. 400-1a; F) L.H.-4 (cast). Scale bar is $2 \mathrm{~cm}$.

Figure 9. Outline of mandibular corpus cross section at $\mathrm{M}_{1}$ of some $A u$. afarensis mandibles from Hadar, Middle Awash, and Laetoli (top and middle row) compared to NFR-VP-1/29 and Au. deyiremeda (BRT-VP-3/14 and WYT-VP-2/10) mandibles from the WoransoMille (bottom row). Note that NFR-VP-1/29 is most similar to A.L. $333 \mathrm{w}-60$ and to some degree MAK-VP-1/12, in terms of having a well-developed superior transverse torus compared to the inferior transverse torus. However, the mandibles of Au. deyiremeda appear to be different from those of $A u$. afarensis in having an extremely broad corpus. The cross sections of $A u$. afarensis mandibles are modified from Kimbel et al.'s (2004) Figure 5.31 which was compiled from cross sections published in White et al., 2000; Brunet et al., 1996; and Ward et al., 2001. All outlines are not to scale.

Figure 10. Premolar root morphology of NFR-VP-1/29. A) Immediately below crown base; B) at mid-root level. Note that the mesial root of the $\mathrm{P}_{3}$ is rounded and mesiobuccally positioned, whereas the distal root is plate-like and has two root canals. The mesial and distal roots of the $\mathrm{P}_{4}$ are both plate-like and have two root canals each. The distal root bifurcates into two roots toward its tip.

Figure 11. Bivariate plots of mandibular dental and corpus dimensions in early-mid Pliocene hominins. The NFR-VP-1/29 dentition and corpus are large, but fall within or border the documented $A u$. afarensis range. Filled black circles: NFR-VP-1/29. Open circles: isolated mandibular teeth from NFR-VP-1. Red squares: Au. afarensis. Blue triangles: 
Au. anamensis. Green diamonds: Au. deyiremeda. Gray crosses: specimens from Lomekwi. $\mathrm{MD}=$ mesiodistal; $\mathrm{BL}=$ buccolingual; $\mathrm{HT}=$ height; $\mathrm{BR}=$ breadth.

Figure 12. Comparison of NFR-VP-1/29 (Au. afarensis) and BRT-VP-3/14 (paratype of $A u$.

deyiremeda). The black arrows show the differences between the two mandibles in terms of the origin of the ascending ramus (1), the size of the extramolar sulcus (2), and corpus inflation at the level of the molars. Scale bar is $2 \mathrm{~cm}$. 
Table 1. NFR-VP-1 faunal list based on 342 catalogued specimens.

Aves

Gen. et sp. indet (large)

Gen. et sp. indet (small)

Bovidae

Aepyceros cf. A. datoadeni

Aepyceros sp.

Antilopini gen. et sp. indet.

Neotragini gen. et sp. indet.

Reduncini gen. et sp. indet.

Tragelaphus kyaloi

Tragelaphus cf. T. lockwoodi

Oryx sp.

Giraffidae

Giraffa sp.

Sivatherium maurusium

Hippopotamidae

Hexaprotodon cf. H. coryndoni

Tayassuidae

cf. Cainochoerus sp.

Suidae

Kolpochoerus afarensis

Notochoerus euilus

Mustelidae

Enhydriodon sp.

Felidae

cf. Dinofelis sp.

Hyaenidae

cf. Crocuta sp.
Canidae

Gen et sp. indet.

Rhinocerotidae

Ceratotherium efficax

Diceros sp.

Soricidae

Gen et sp. indet.

Equidae

Eurygnathohippus hasumense

Cercopithecidae

Papionini gen et sp. indet.

Theropithecus oswaldi aff. spp.

Colobinae gen et sp. indet.

Hominidae

Australopithecus afarensis

Hystricidae

Hystrix sp.

Thryonomyidae

Thryonomys sp.

Orycteropodidae

Orycteropus sp.

Elephanitdae

Elephas recki

Squamata

Teleost

Chelonia

Crocodylidae 
Table 2. Stable carbon and oxygen isotope data of fossil teeth from Nefuraytu.

\begin{tabular}{|c|c|c|c|c|c|c|c|c|}
\hline Specimen & Taxon & Element & $\delta^{13} \mathrm{C}$ avg* & $\delta^{13} \mathrm{Cstdv}$ & $\delta^{18} \mathrm{O}$ avg & $\delta^{18} 0 \mathrm{stdv}$ & $\mathbf{n}$ & Strat position* \\
\hline NFR-VP-1/213 & Hominini gen. sp. inde & LM3 & -9.1 & -- & 1.1 & -- & 1 & Lower \\
\hline NFR-VP-1/125 & Bovidae gen. sp. Indet & molar & -10.1 & -- & 2.3 & -- & 1 & Upper \\
\hline NFR-VP-1/146 & Tragelaphus sp. & molar & -5.8 & -- & -1.5 & -- & 1 & Lower \\
\hline NFR-VP-1/152 & Tragelaphus sp. & molar & -8.4 & -- & 6.3 & -- & 1 & Lower \\
\hline NFR-VP-1/154 & Tragelaphus sp. & molar & -8.7 & 0.4 & 4.8 & 0.0 & 2 & Lower \\
\hline NFR-VP-1/42 & Sivatherium sp. & molar & -9.7 & -- & 3.6 & -- & 1 & Upper \\
\hline NFR-VP-1/133 & Sivatherium sp. & molar frag. & -9.1 & -- & 2.6 & -- & 1 & Upper \\
\hline NFR-VP-1/134 & Giraffa sp. & molar & -10.5 & -- & 4.5 & -- & 1 & Upper \\
\hline NFR-VP-1/1 & Notochoerus euilus & M3 & -1.8 & -- & -1.1 & -- & 1 & Lower \\
\hline NFR-VP-1/7A & Notochoerus euilus & M3 & -0.7 & -- & -0.4 & -- & 1 & Lower \\
\hline NFR-VP-1/14 & Notochoerus euilus & (M3?) frag. & -0.6 & -- & 0.7 & -- & 1 & Lower \\
\hline NFR-VP-1/16 & Notochoerus euilus & M3 & -0.6 & 0.1 & 2.2 & 0.0 & 2 & Lower \\
\hline NFR-VP-1/20 & Notochoerus euilus & M3 & 0.1 & -- & 3.5 & -- & 1 & Lower \\
\hline NFR-VP-1/24 & Notochoerus euilus & M3 & -0.2 & 0.0 & 1.0 & 0.2 & 2 & Lower \\
\hline NFR-VP-1/34 & Notochoerus euilus & M3 & -0.7 & -- & -1.2 & -- & 1 & Lower \\
\hline NFR-VP-1/50 & Notochoerus euilus & M3 & -2.4 & -- & -4.9 & -- & 1 & Lower \\
\hline NFR-VP-1/190 & Notochoerus euilus & M3 & -1.6 & -- & 1.5 & -- & 1 & Lower \\
\hline NFR-VP-1/197 & Notochoerus euilus & M3 & -3.6 & -- & -2.3 & -- & 1 & Lower \\
\hline NFR-VP-1/227 & Notochoerus euilus & M3 & -0.4 & -- & -2.1 & -- & 1 & Upper \\
\hline
\end{tabular}

All data were originally published in Levin et al. (2015).

${ }^{*} \delta^{13} \mathrm{C}$ values are reported in \%o units relative to VPDB. Mean ${ }^{13} \mathrm{C}$ values are reported if the powder tooth enamel was measured multiple times.

**Strat position refers to whether the specimen was found associated with the upper or lower fossiliferous horizon at Nefuraytu. 
Table 3. Stable carbon and oxygen isotope data from pedogenic carbonates at Nefuraytu.

\begin{tabular}{lccccccc} 
Sample ID & $\boldsymbol{\delta}^{\mathbf{1 3}} \mathbf{C}$ avg & $\boldsymbol{\delta}^{\mathbf{1 3}} \mathbf{C} \mathbf{s t d v}$ & $\boldsymbol{\delta}^{\mathbf{1 8}} \mathbf{O}$ avg & $\boldsymbol{\delta}^{\mathbf{1 8}} \mathbf{O}$ stdv & $\mathbf{n}$ & Latitude & Longitude \\
\hline & & & & & & & \\
WM11-NFR-154 & -2.5 & 0.9 & -8.2 & 0.2 & 3 & 11.47341 & 40.58930 \\
WM11-NFR-155 & -7.4 & 0.3 & -3.3 & 0.6 & 2 & 11.47226 & 40.58846 \\
WM11-NFR-156 & -11.6 & -- & -1.5 & -- & 1 & 11.47072 & 40.58766 \\
WM11-NFR-158 & -11.5 & 0.3 & -5.2 & 0.0 & 2 & 11.47088 & 40.58801
\end{tabular}

Mean values are reported if multiple carbonate nodules from a single paleosol were sampled. Latitude and longitude are reported relative to the WGS84 datum. All data were initially reported in Levin et al. (2015). Note that some cooordinates have been updated from what is reported in Levin et al. (2015); the coordinates reported here are correct. 
Table 4. Abbreviations of dental and directional terminology used in the comparative description (adopted from Johanson and White, 1982).

\begin{tabular}{|l|l|}
\hline $\mathrm{Pa}=$ paracone & $\mathrm{Fa}=$ anterior fovea \\
$\mathrm{Pr}=$ protocone & $\mathrm{Fp}=$ posterior fovea \\
$\mathrm{Me}=$ metacone & $\mathrm{Fc}=$ central fovea \\
$\mathrm{Hy}=$ hypocone & $\mathrm{Mmr}=$ mesial marginal ridge \\
Prd = protoconid & $\mathrm{Dmr}=$ distal marginal ridge \\
$\mathrm{Med}=$ metaconid & $\mathrm{MD}=$ mesiodistal(ly) \\
$\mathrm{Hyd}=$ hypoconid & $\mathrm{BL}=$ buccolingual(ly) \\
$\mathrm{Hld}=$ hypoconulid & $\mathrm{LaL}=$ labiolingual(ly) \\
End = entoconid & $\mathrm{AP}=$ anteroposterior(ly) \\
$\mathrm{C} 6=$ tuberculum sextum & $\mathrm{SI}=$ superoinferior(ly) \\
$\mathrm{IPF}=$ interproximal facet & $\mathrm{ML}=$ mediolateral(ly) \\
$\mathrm{Mlg}=$ median longitudinal groove & $\mathrm{L}=$ Left \\
$\mathrm{CEJ}=$ cervicoenamel junction & $\mathrm{R}=$ Right \\
& \\
\hline
\end{tabular}


Table 5. Mandibular dimensions of NFR-VP-1/29. Values in parentheses are best estimates. All measurements are in $\mathrm{mm}$.

\begin{tabular}{|c|c|c|c|c|c|c|c|c|}
\hline $\begin{array}{c}\text { At crowns } \\
\text { Between crowns }\end{array}$ & $\mathrm{I}_{1} / \mathrm{I}_{1}$ & $\mathrm{I}_{1} / \mathrm{I}_{2}$ & $\begin{array}{c}\mathrm{C} \\
\mathrm{I}_{2} / \mathrm{C}\end{array}$ & $\begin{array}{c}\mathrm{P}_{3} \\
\mathrm{C} / \mathrm{P}_{3} \\
\end{array}$ & $\begin{array}{c}\mathrm{P}_{4} \\
\mathrm{P}_{3} / \mathrm{P}_{4} \\
\end{array}$ & $\begin{array}{c}\mathrm{M}_{1} \\
\mathrm{P}_{4} / \mathrm{M}_{1} \\
\end{array}$ & $\begin{array}{c}\mathrm{M}_{2} \\
\mathrm{M}_{1} / \mathrm{M}_{2} \\
\end{array}$ & $\begin{array}{c}\mathrm{M}_{3} \\
\mathrm{M}_{2} / \mathrm{M}_{3} \\
\end{array}$ \\
\hline \multicolumn{9}{|l|}{ Perpendicular corpus height } \\
\hline Midline & 43.7 & & & & & & & \\
\hline Right at crowns & & & & & 39.7 & 37.7 & 33 & - \\
\hline Right between crowns & & $(44.5)$ & $(42.4)$ & 40.8 & 41.6 & 39.1 & 35.1 & 32 \\
\hline Left at crowns & & & & & 39.4 & 38.1 & 34.9 & 32.9 \\
\hline Left between crowns & & & & 41.2 & 41 & 39.6 & 36.6 & 33.7 \\
\hline \multicolumn{9}{|l|}{ Minimum corpus breadth } \\
\hline Midline & 23.5 & & & & & & & \\
\hline Right at crowns & & - & 25.1 & 23.5 & 21.5 & 22 & 24.9 & 26.6 \\
\hline Right between crowns & & 24.1 & 24.8 & 23.5 & 22.9 & 21.9 & 22.6 & 26 \\
\hline Left at crowns & & 23.1 & - & 24.5 & 23.4 & 23.3 & 24.8 & 28.3 \\
\hline \multirow[t]{2}{*}{ Left between crowns } & & - & - & 24.9 & 23.2 & 22.8 & 25.7 & 27.8 \\
\hline & & & $\mathrm{C}$ & $\mathrm{P}_{3}$ & $\mathrm{P}_{4}$ & $\mathrm{M}_{1}$ & $\mathrm{M}_{2}$ & $\mathrm{M}_{3}$ \\
\hline Bi-internal alveolar margin breadth & & & $(18.3)$ & 28.1 & 33.4 & 34.7 & 37.3 & 44.2 \\
\hline Bi-crown center breadth & & & - & $(39.5)$ & 42.8 & 47.1 & 48.5 & 52.3 \\
\hline
\end{tabular}


Table 6. Dental measurements of NFR-VP-1/29 and summary statistics of Au. anamensis and Au. afarensis.

\begin{tabular}{|c|c|c|c|c|c|c|c|c|c|c|}
\hline \multirow{2}{*}{$\begin{array}{l}\text { Specimen/ } \\
\text { Taxon }\end{array}$} & \multicolumn{2}{|c|}{$\mathrm{I}_{2}$} & \multicolumn{2}{|c|}{$\mathrm{P}_{4}$} & \multicolumn{2}{|c|}{$\mathrm{M}_{1}$} & \multicolumn{2}{|c|}{$\mathrm{M}_{2}$} & \multicolumn{2}{|c|}{$M_{3}$} \\
\hline & $M D$ & LaL & $M D$ & $\mathrm{BL}$ & $\mathrm{MD}$ & $B L$ & $M D$ & $\mathrm{BL}$ & $\mathrm{MD}$ & $B L$ \\
\hline \multicolumn{11}{|l|}{ NFR-VP-1/29 } \\
\hline $\mathrm{R}$ & - & - & 10.8 & 12.3 & 14.5 & - & 15.7 & 14.9 & 17.1 & 15.2 \\
\hline $\mathrm{L}$ & 6.6 & 8.5 & 10.5 & 12.5 & 14.3 & 13.8 & 15.6 & 15 & 17.3 & 14.7 \\
\hline Average & - & - & 10.65 & 12.4 & 14.4 & - & 15.65 & 14.95 & 17.2 & 14.95 \\
\hline
\end{tabular}

Au. anamensis

\begin{tabular}{rcccccccccc}
$n$ & 2 & 3 & 8 & 8 & 10 & 10 & 7 & 7 & 7 & 7 \\
Average & 8.5 & 8.3 & 9.09 & 11.34 & 12.56 & 11.72 & 14.71 & 13.4 & 15.41 & 13.54 \\
Range & $(8.4-8.6)$ & $(7.7-8.7)$ & $(7.3-10.1)$ & $(9.5-13.2)$ & $(11.6-13.8)$ & $(10.4-13.5)$ & $(13.8-16.1)$ & $(12.2-14.9)$ & $(13.9-17.2)$ & $(12.1-15.1)$ \\
Stdv & - & 0.53 & 0.95 & 1.33 & 0.89 & 0.91 & 0.94 & 0.93 & 1.28 & 0.88 \\
\hline
\end{tabular}

Au. afarensis

\begin{tabular}{rcccccccccc}
$n$ & 5 & 5 & 19 & 19 & 22 & 22 & 28 & 28 & 21 & 21 \\
Average & 6.2 & 8.2 & 9.78 & 11.06 & 13.18 & 12.63 & 14.27 & 13.42 & 15.2 & 13.37 \\
Range & $(5.0-7.2)$ & $(6.7-8.8)$ & $(7.7-11.4)$ & $(9.8-12.8)$ & $(11.2-14.8)$ & $(11.0-14.0)$ & $(12.4-16.2)$ & $(11.1-15.2)$ & $(13.4-18.1)$ & $(11.3-15.3)$ \\
Stdv & 0.85 & 0.86 & 1.06 & 0.81 & 0.77 & 0.81 & 1.15 & 0.96 & 1.27 & 0.94 \\
\hline
\end{tabular}

Measurements were compiled from White $(1977,1980)$, Johanson and White (1982), Ward et al. (2001), Kimbel et al. (2004), White et al. (2006), and Ward (2014). $R$ = right; $L=$ left; AVG = average; Stdv = standard deviation. All measurements are in $\mathrm{mm}$. 
Table 7. Crown shape index $(=(B L / M D) * 100)$ and crown size $(=\sqrt{ }(M D * B L))$ in early-middle Pliocene hominins.

Boldface indicates a significant difference between Au. anamensis and Au. afarensis $(p<0.05)$ using a t-test.

\begin{tabular}{|c|c|c|c|c|c|c|c|c|c|c|c|c|c|}
\hline & & & & & & & \multicolumn{4}{|c|}{ NFR-VP- } & & \multicolumn{2}{|c|}{ KNM-WT } \\
\hline & \multicolumn{3}{|c|}{ Au. anamensis } & \multicolumn{3}{|c|}{ Au. afarensis } & \multirow[t]{2}{*}{$1 / 29$} & \multirow[t]{2}{*}{$1 / 2$} & \multirow[t]{2}{*}{$1 / 58$} & \multirow[t]{2}{*}{$1 / 213$} & \multirow[t]{2}{*}{ Au.deyiremeda } & \multirow[t]{2}{*}{8556} & \multirow[t]{2}{*}{16006} \\
\hline & $n$ & $\bar{x}$ & $\sigma$ & $n$ & $\bar{x}$ & $\sigma$ & & & & & & & \\
\hline $\mathrm{I}_{2}$ & 1 & & & 4 & & & & & & & & & \\
\hline shape & & 98.8 & -- & & 126.9 & 31.5 & 128.8 & & & & & & \\
\hline size & & 8.5 & -- & & 7.0 & 0.6 & 7.5 & & & & & & \\
\hline $\mathrm{P}_{4}$ & 8 & & & 19 & & & & & & & & & \\
\hline shape & & 125.0 & 10.0 & & 113.8 & 10.1 & 116.5 & & & & 129.3 & 111.6 & \\
\hline size & & 10.1 & 1.0 & & 10.4 & 0.9 & 11.5 & & & & 9.3 & 11.8 & \\
\hline $\mathrm{M}_{1}$ & 10 & & & 22 & & & & & & & & & \\
\hline shape & & 93.4 & 4.4 & & 95.9 & 3.7 & 96.5 & 85.6 & & & 100 & 93.6 & \\
\hline size & & 12.1 & 0.9 & & 12.9 & 0.8 & 14.1 & 12.9 & & & 10.6 & 13.5 & \\
\hline $\mathrm{M}_{2}$ & 7 & & & 28 & & & & & & & & & \\
\hline shape & & 91.1 & 3.3 & & 94.2 & 5.4 & 95.5 & & 89.3 & & 98.6 & & \\
\hline size & & 14.0 & 0.9 & & 13.8 & 1.0 & 15.3 & & 14.1 & & 13.9 & & \\
\hline $\mathrm{M}_{3}$ & 7 & & & 21 & & & & & & & & & \\
\hline shape & & 88.2 & 6.5 & & 88.4 & 5.1 & 86.9 & & & & 98.7 & & 86.4 \\
\hline size & & 14.4 & 0.9 & & 14.2 & 7.2 & 16.0 & & & & 15.3 & & 14.3 \\
\hline $\mathrm{M}^{3}$ & 10 & & & 13 & & & & & & & & & \\
\hline shape & & 119.5 & 7.8 & & 115.7 & 5.5 & & & & 108.7 & & & \\
\hline size & & 13.0 & 1.0 & & 13.3 & 1.2 & & & & 13.2 & & & \\
\hline
\end{tabular}


FigureV

\section{Figure 1}

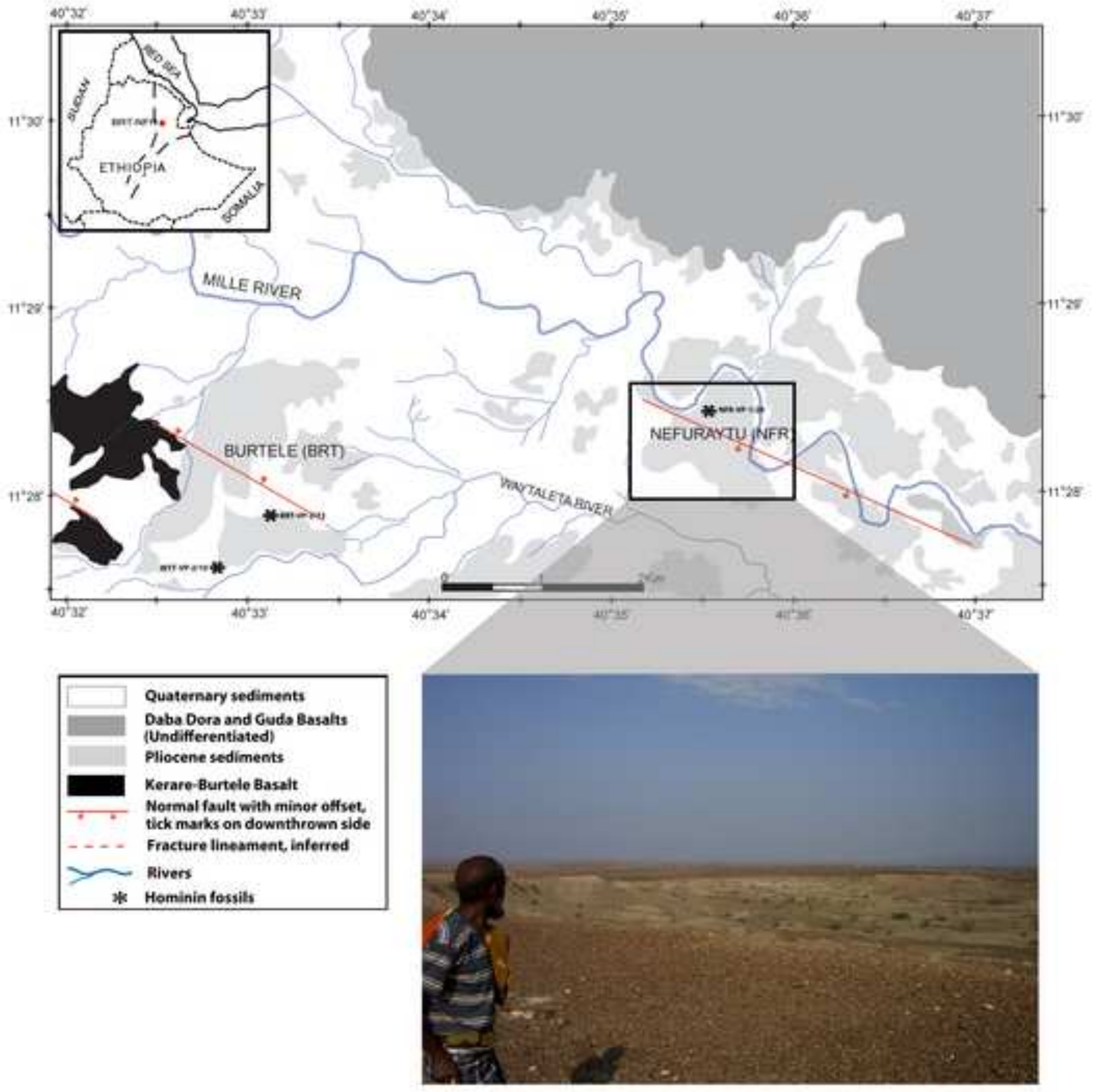



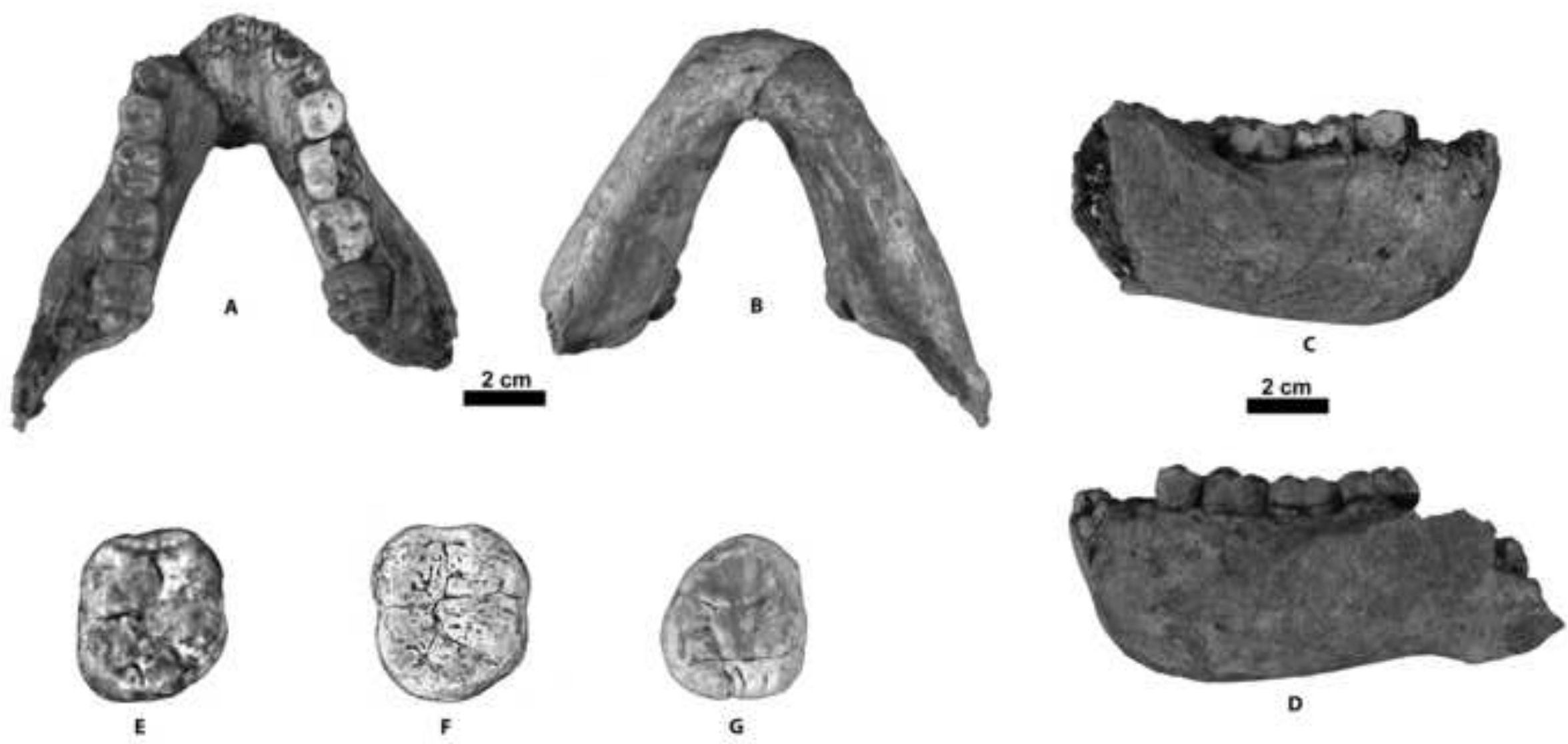

$1 \mathrm{~cm}$ 


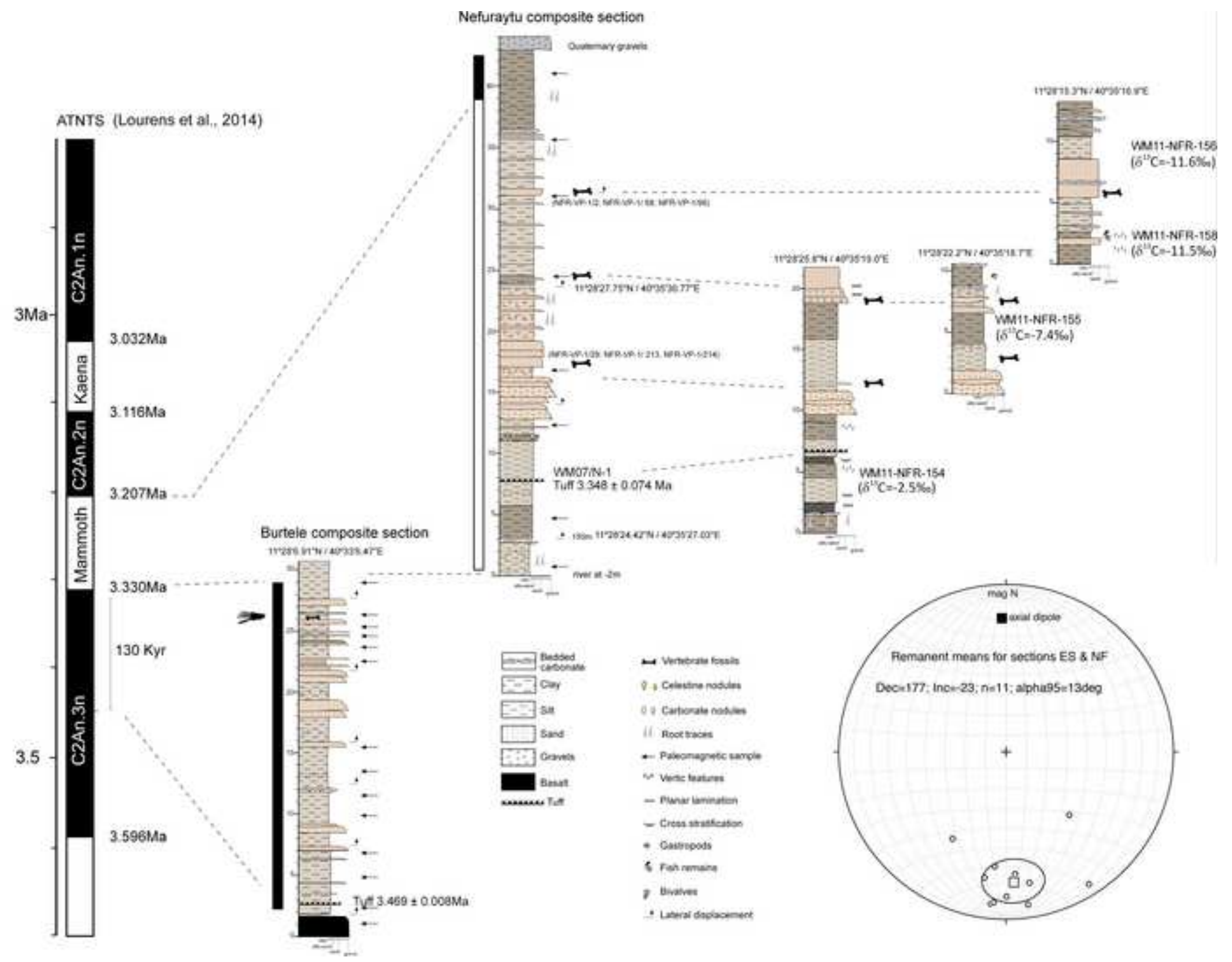




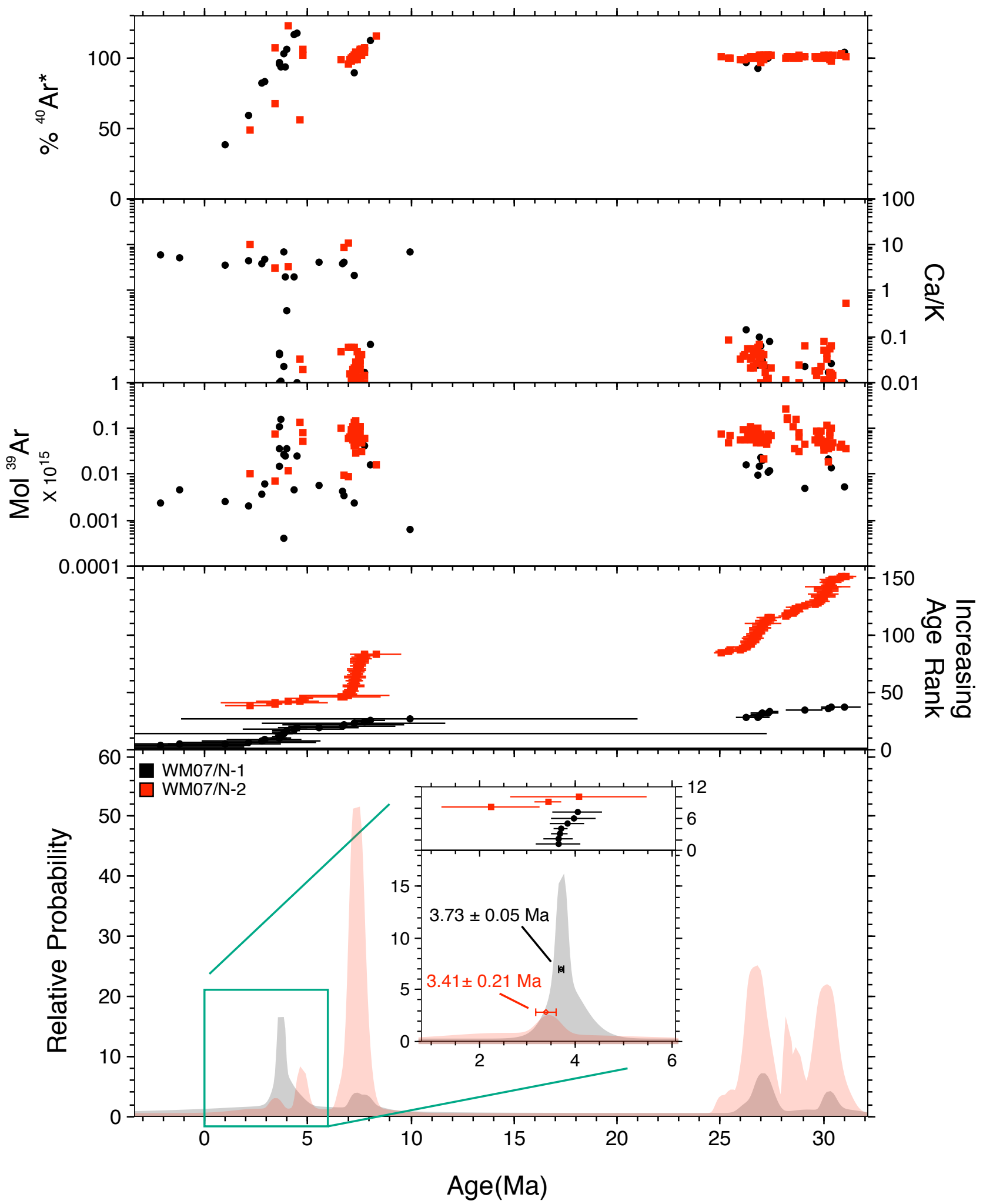




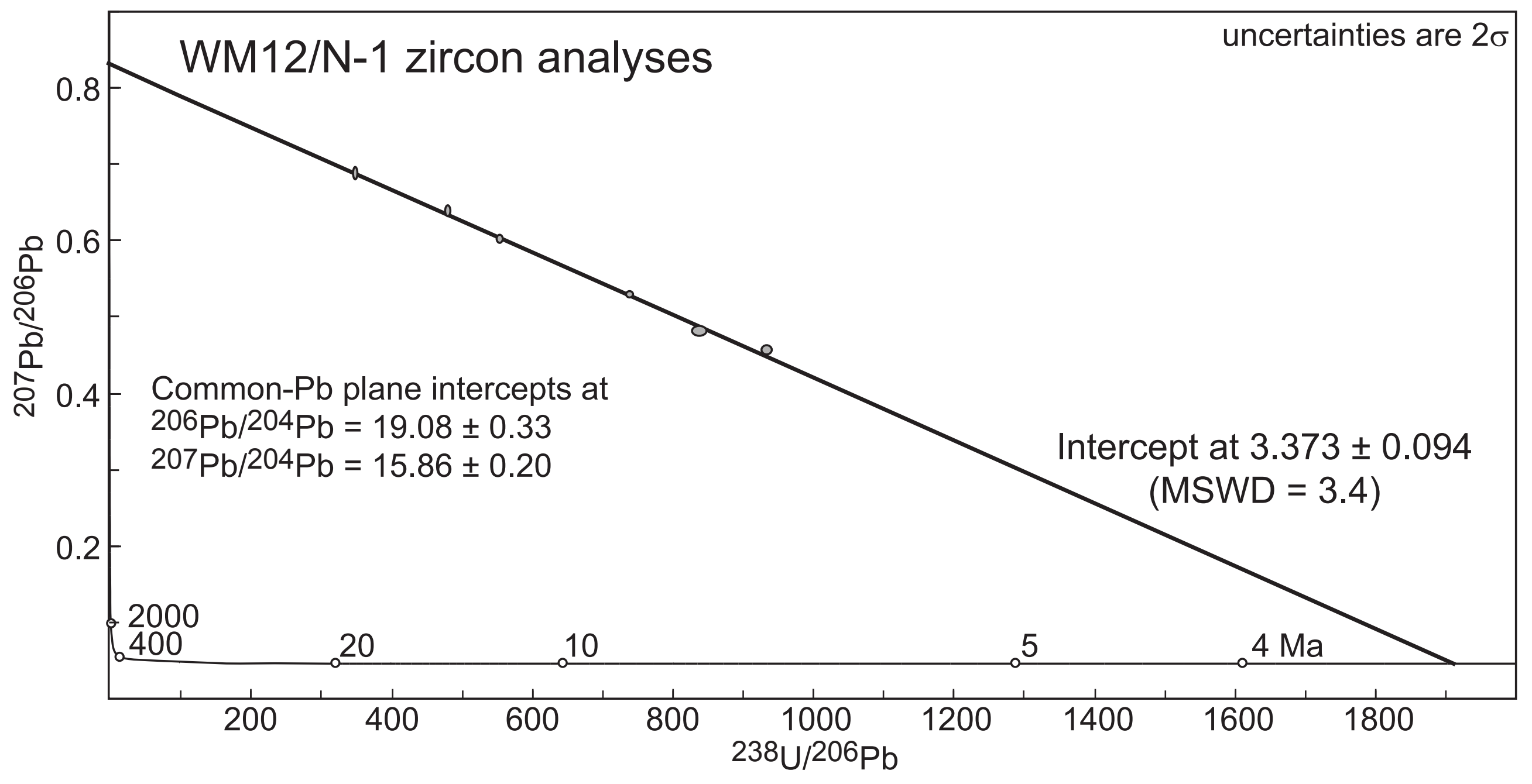




$$
A_{n \cap} \wedge
$$




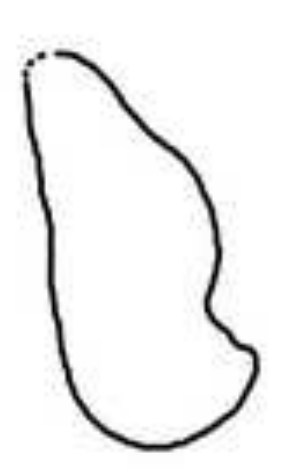

A.L. 417-1a

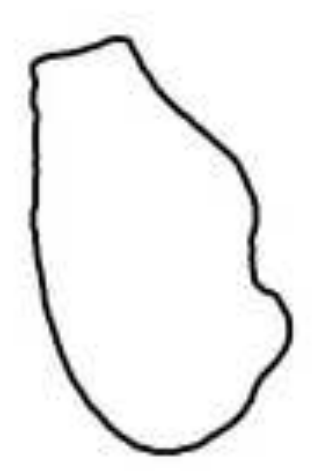

A.L. 437-1
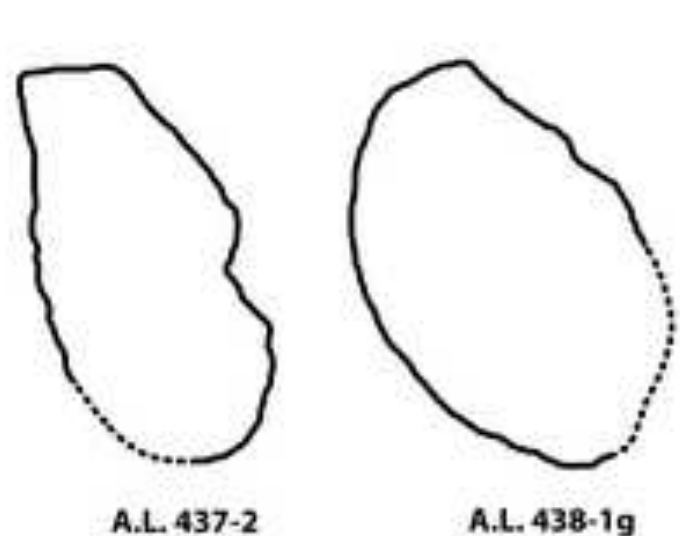

A.L. 438-19
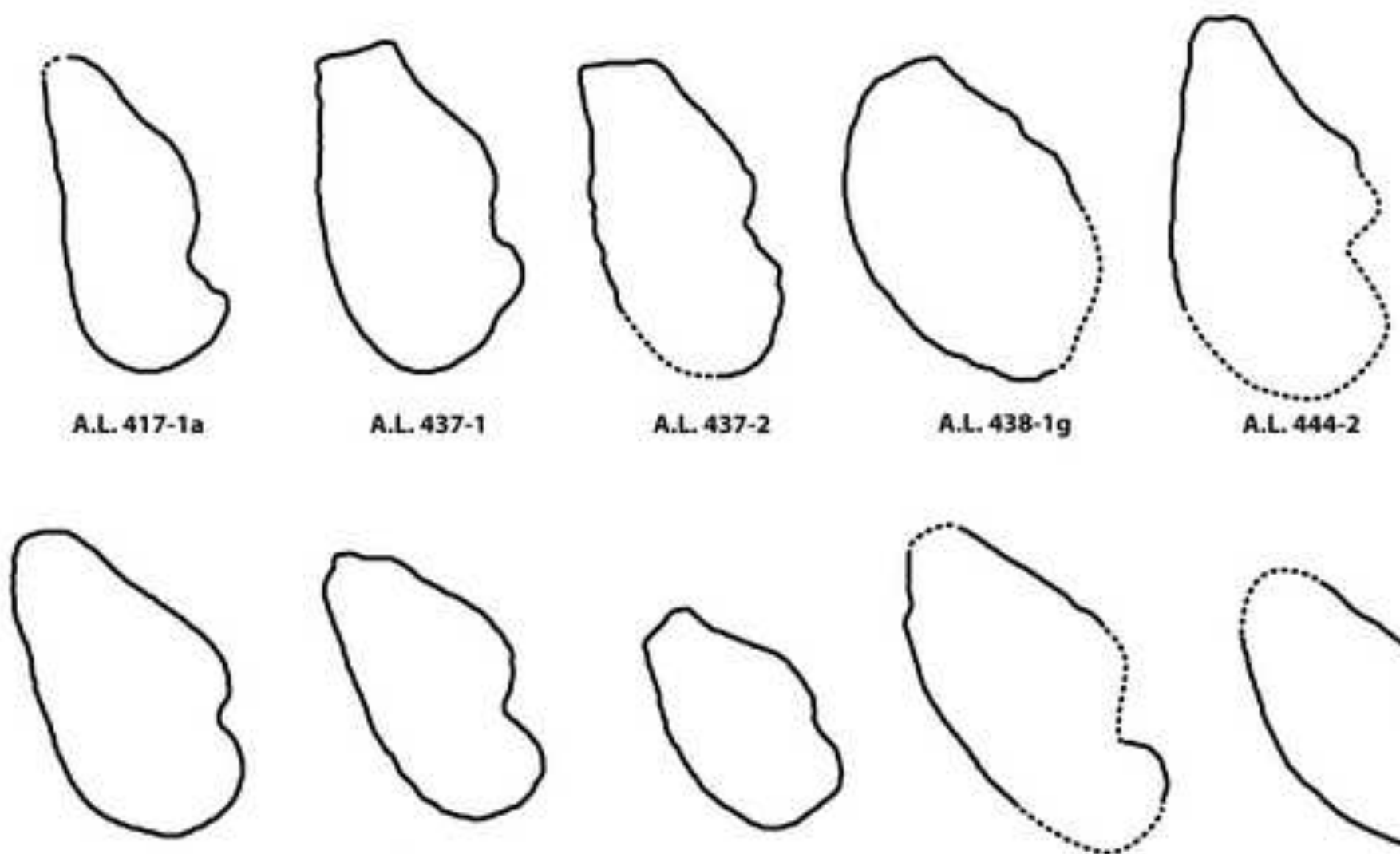

MAK-VP-1/12

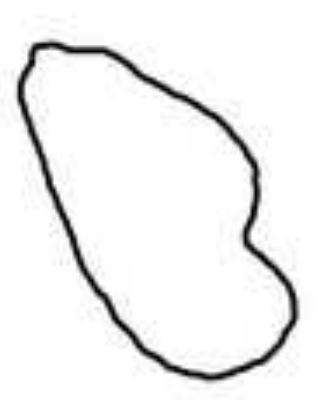

A.L. $400-1 \mathrm{a}$

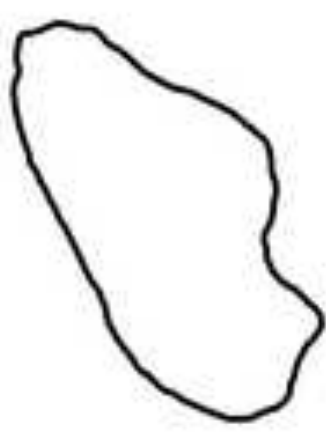

NFR-VP-1/29

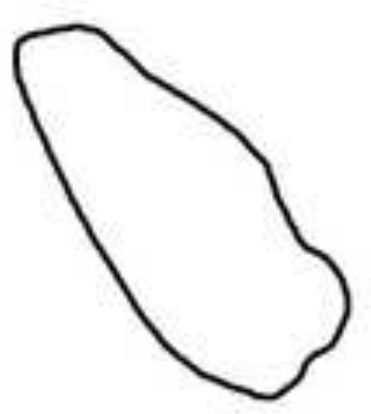

BRT-YP-3/14
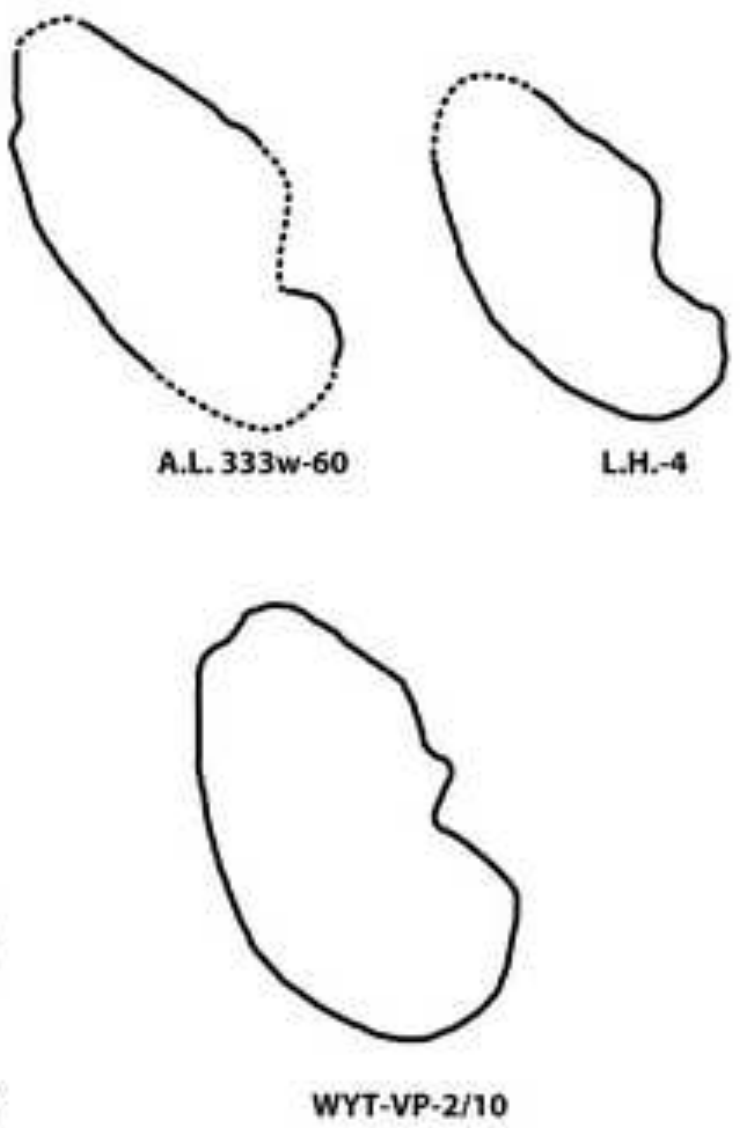

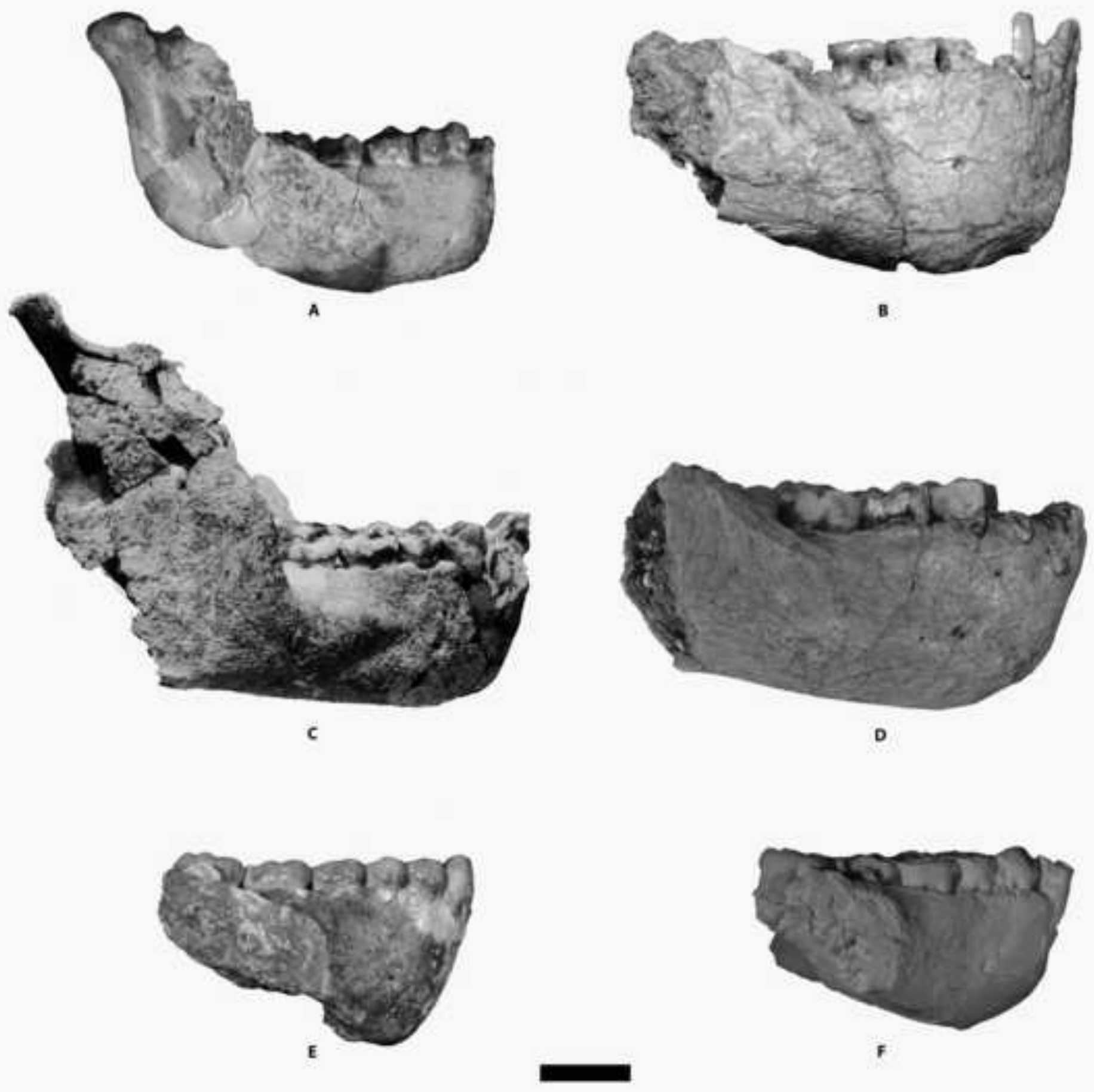

Figure 8

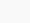


Figure 9

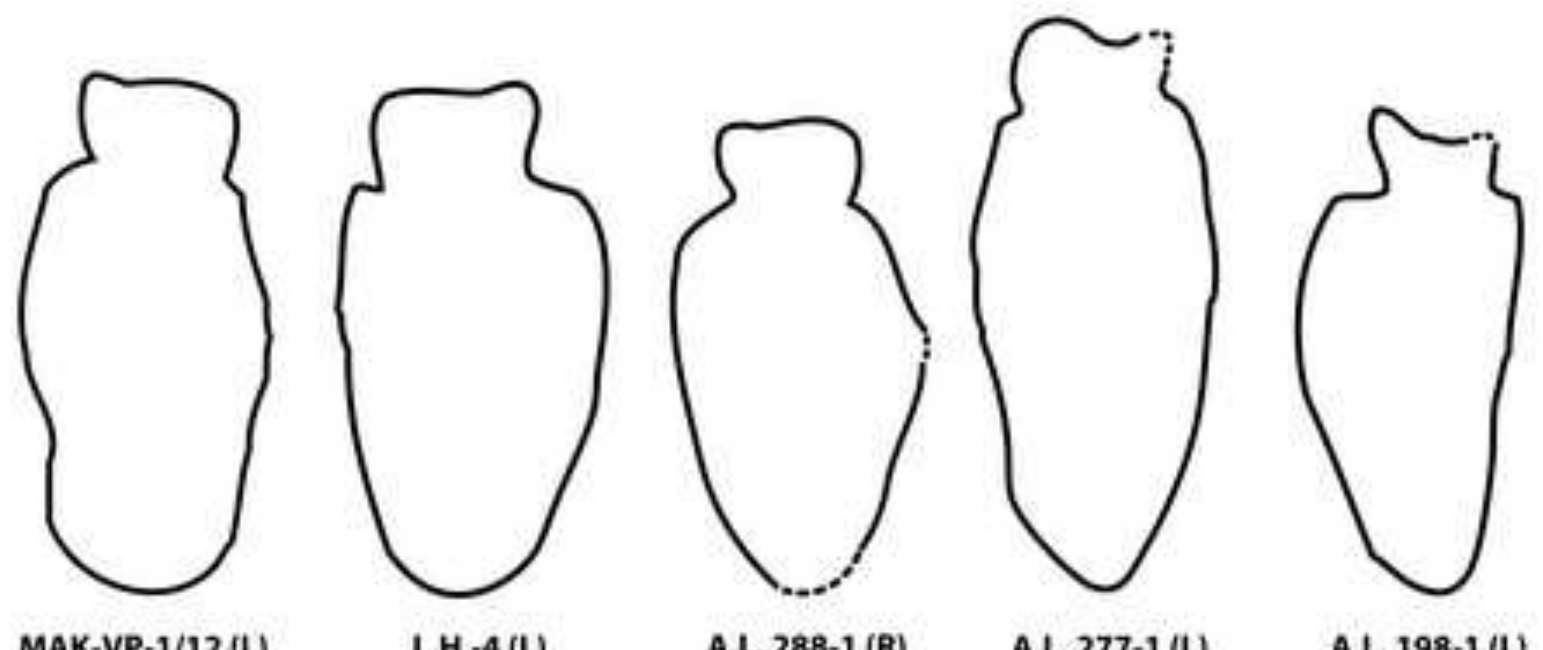

MAK-VP-1/12 (L)

L.H. -4 (L)

A.L. 288-1 (R)

A.L. 277-1 (L)

A.L. 198-1 (L)

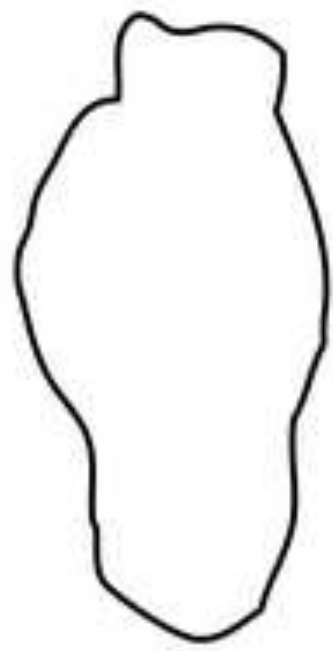

A.L. $333 w-60$ (L)

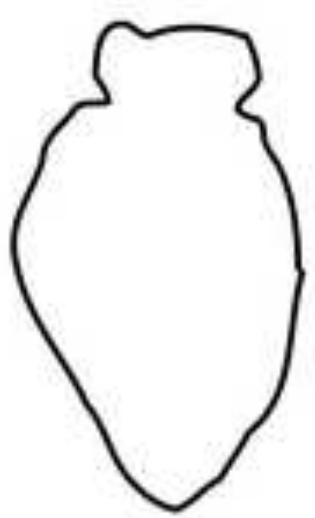

A.L. 266-1 (R)

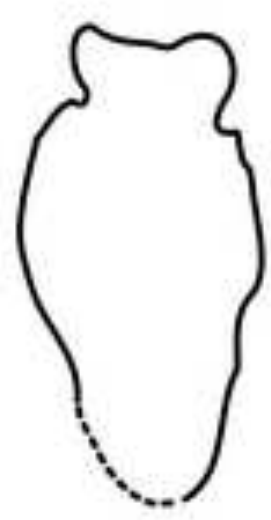

A.L. 333 w-12 (R)

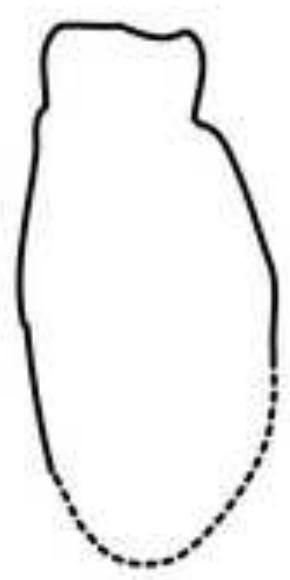

A.L. 400-1a (R)

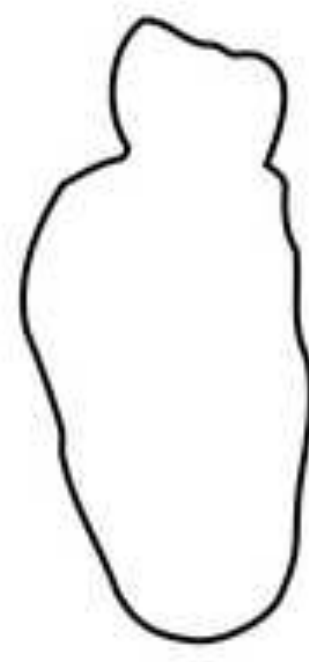

NFR-VP-1/29 (L)

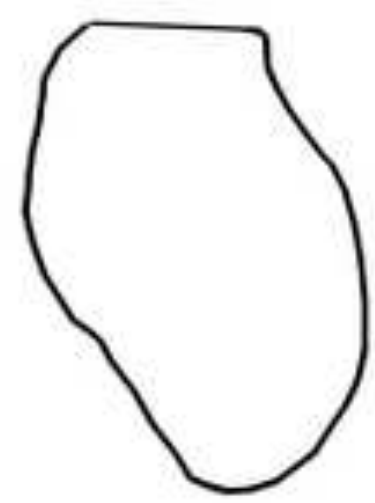

BRT-VP-3/14

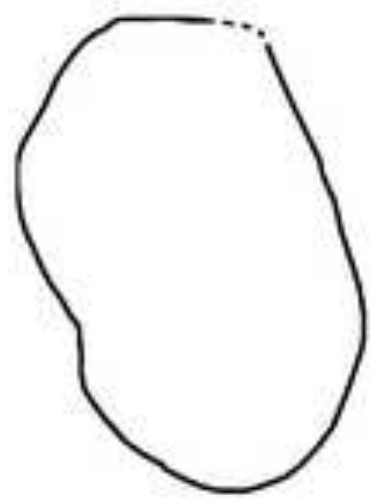

WYT-VP-2/10 

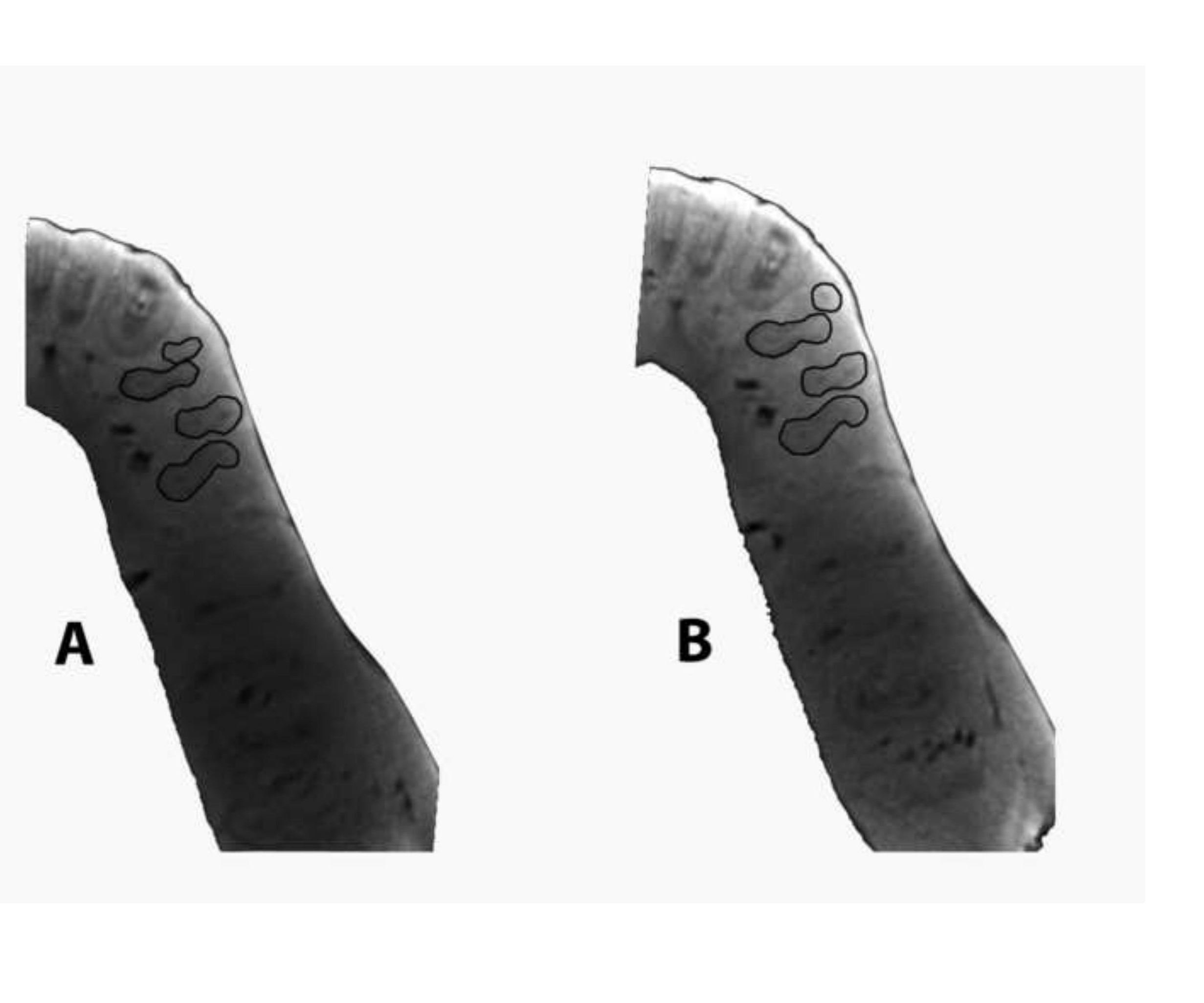

\section{Figure 1

\section{.}
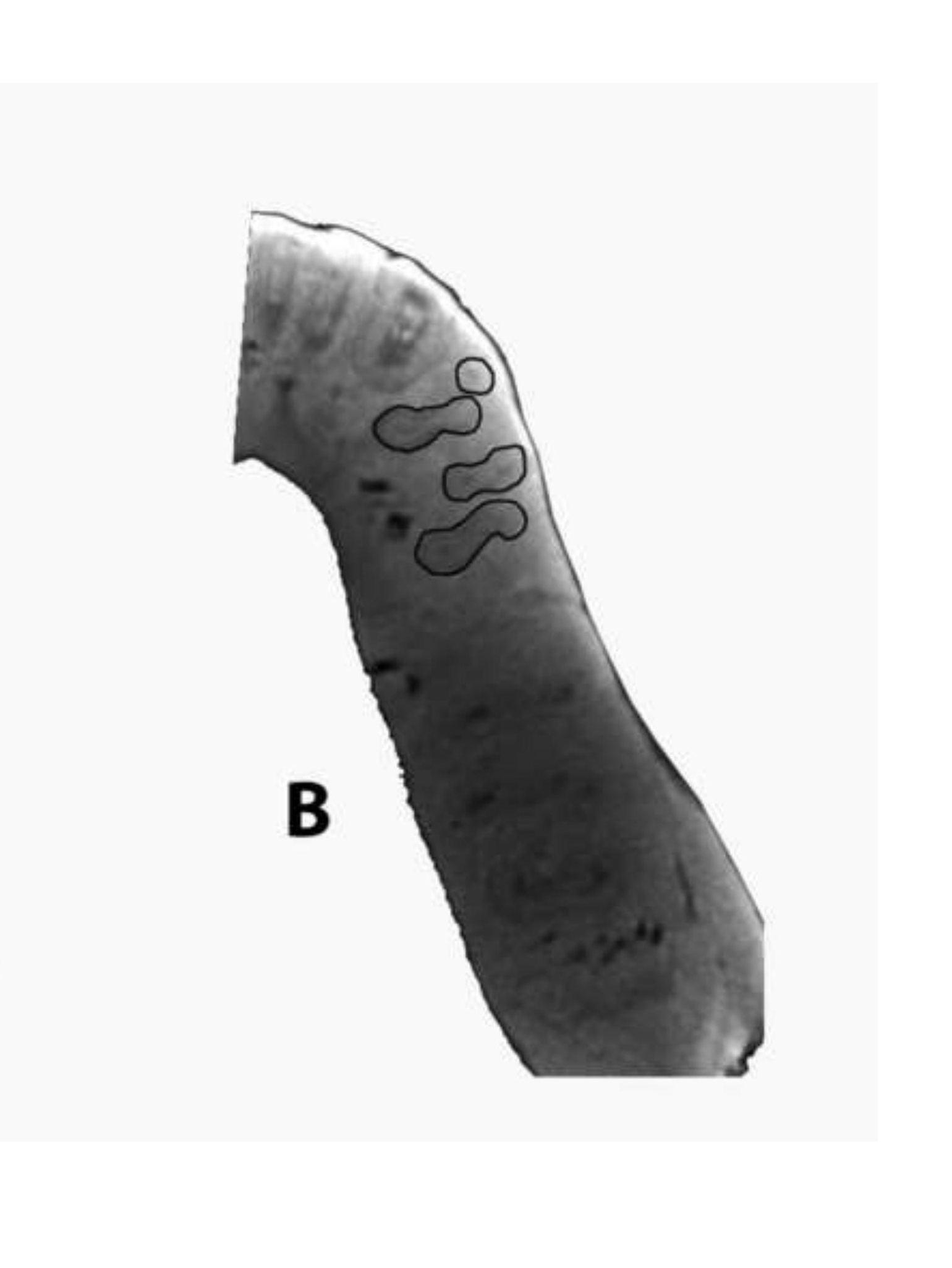

.
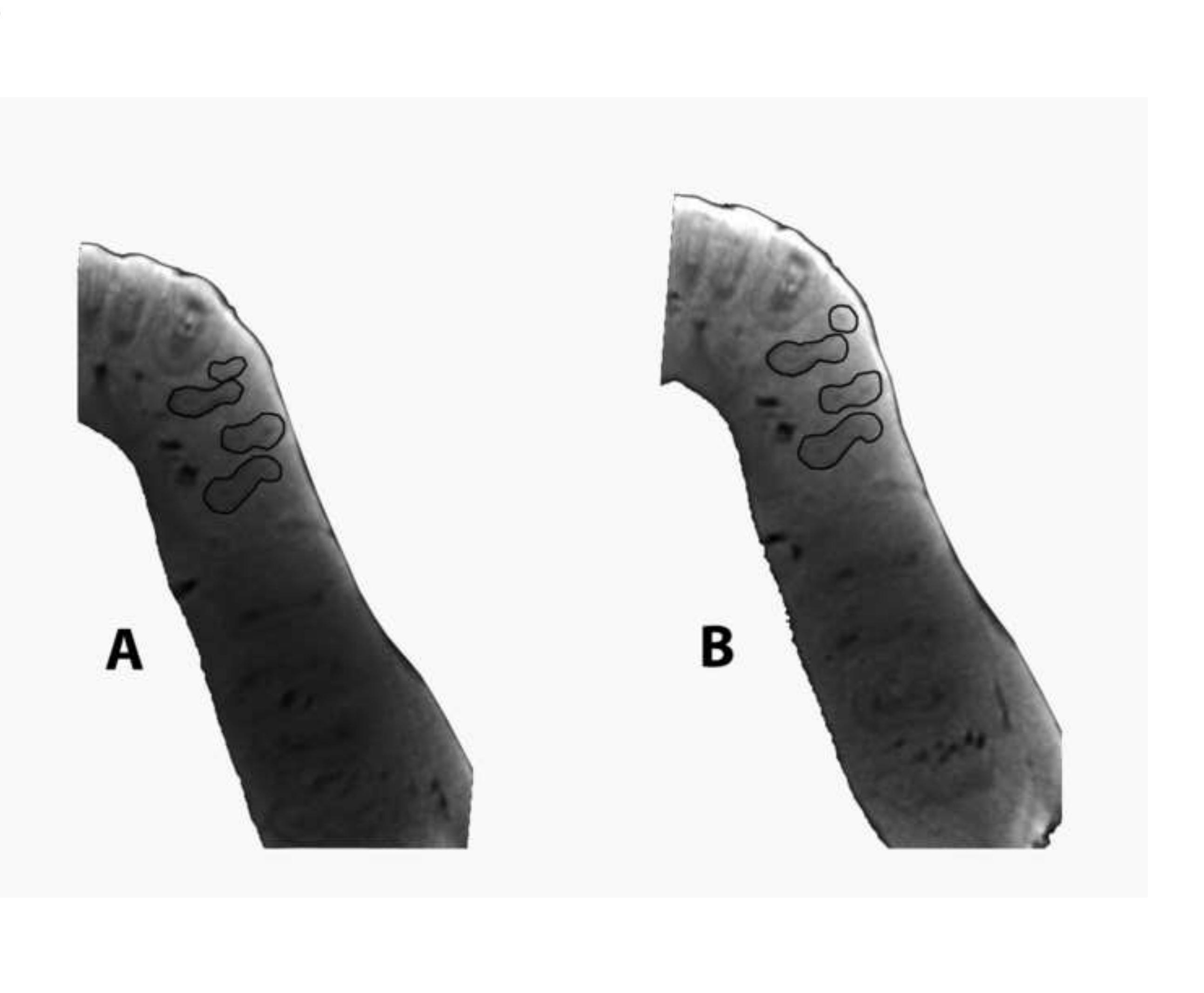

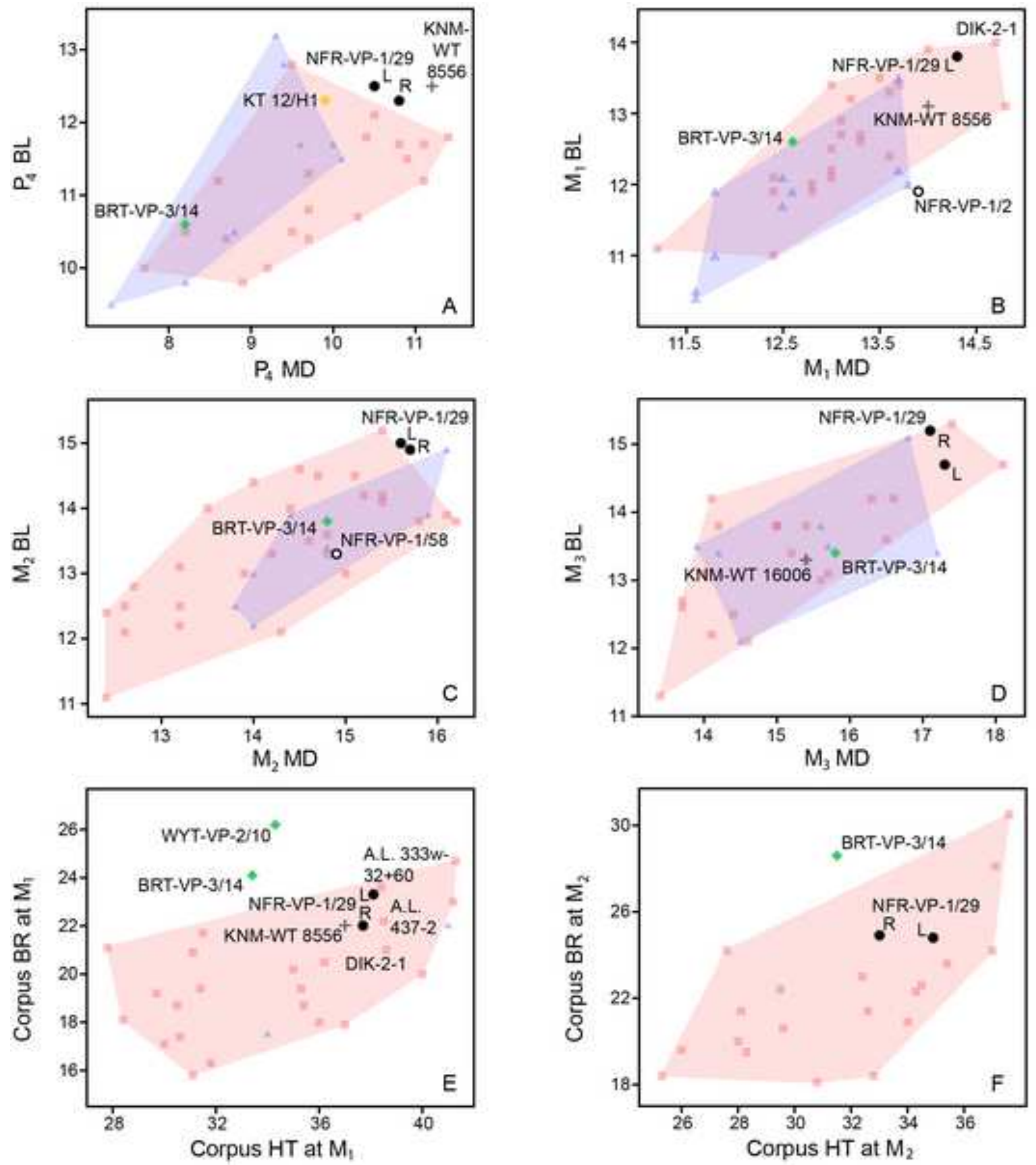

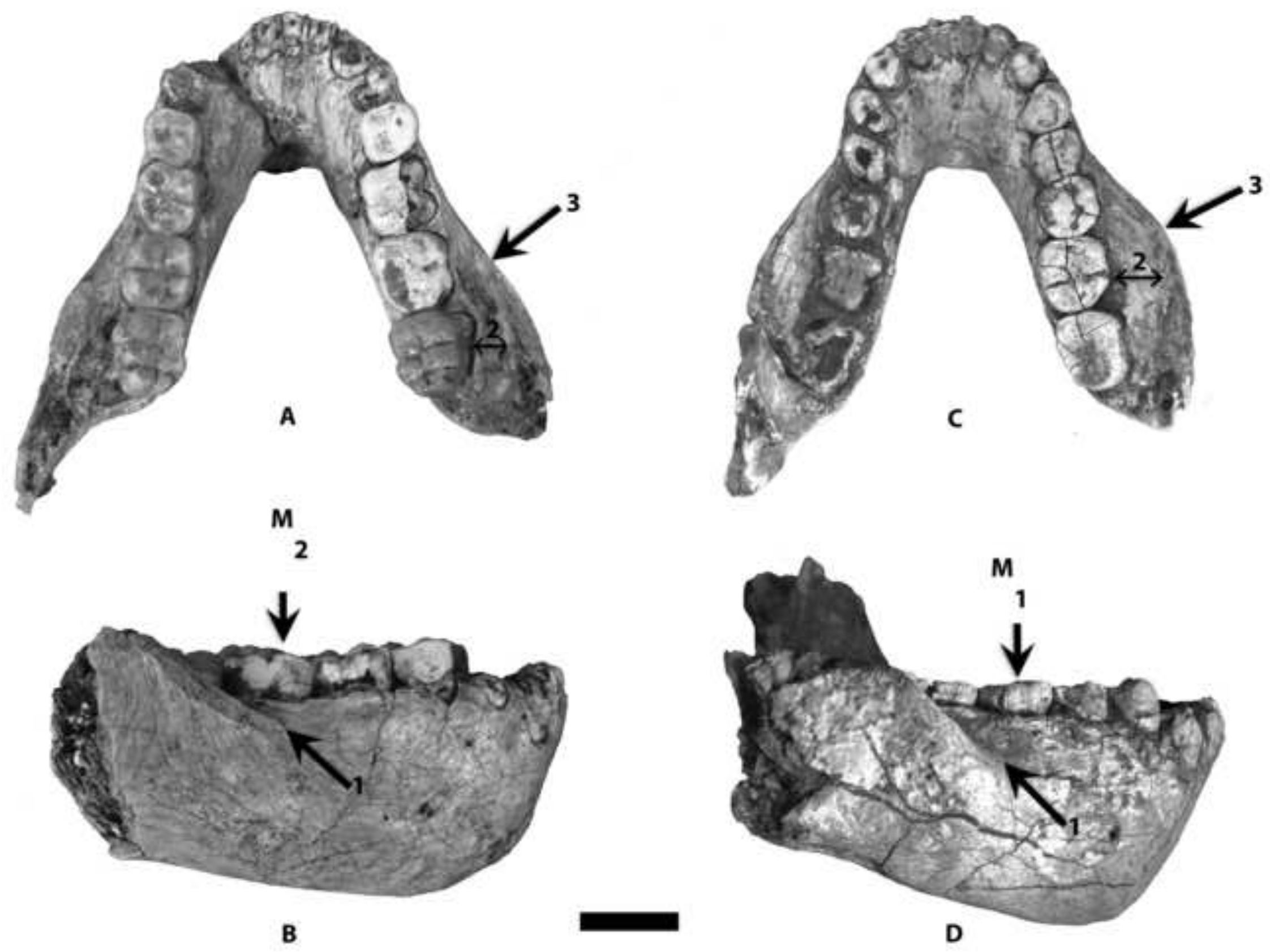

B

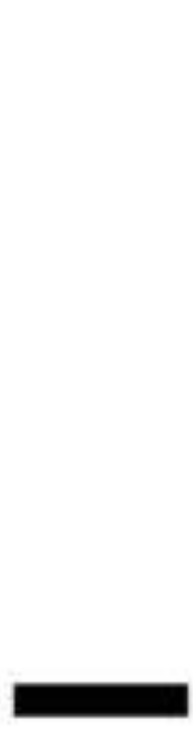

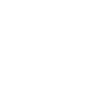

